\title{
Smartphone Applications Targeting Precision Agriculture Practices-A Systematic Review
}

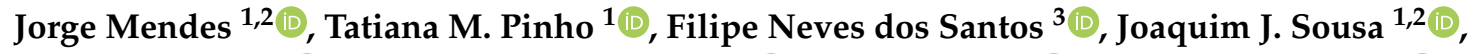 \\ Emanuel Peres ${ }^{1,2}\left(\mathbb{D}\right.$, José Boaventura-Cunha ${ }^{1,2}\left(\mathbb{D}\right.$, Mário Cunha ${ }^{3}$ and Raul Morais $1,2, *(\mathbb{D})$ \\ 1 INESC TEC - Institute for Systems and Computer Engineering, Technology and Science, Pólo da UTAD, \\ University of Trás-os-Montes e Alto Douro, 5000-801 Vila Real, Portugal; jorge.m.mendes@inesctec.pt (J.M.); \\ tatiana.m.pinho@inesctec.pt (T.M.P.); jjsousa@utad.pt (J.J.S.); eperes@utad.pt (E.P.); jboavent@utad.pt (J.B.-C.) \\ 2 UTAD-University of Trás-os-Montes e Alto Douro, Quinta de Prados, 5000-801 Vila Real, Portugal \\ 3 INESC TEC-Institute for Systems and Computer Engineering, Technology and Science, Pólo da FEUP, \\ Faculdade de Engenharia da Universidade do Porto, 4200-465 Porto, Portugal; fbsantos@inesctec.pt \\ (F.N.d.S.); mario.cunha@inesctec.pt (M.C.) \\ * Correspondence: rmorais@utad.pt
}

Received: 1 May 2020; Accepted: 11 June 2020; Published: 16 June 2020

\begin{abstract}
Traditionally farmers have used their perceptual sensorial systems to diagnose and monitor their crops health and needs. However, humans possess five basic perceptual systems with accuracy levels that can change from human to human which are largely dependent on the stress, experience, health and age. To overcome this problem, in the last decade, with the help of the emergence of smartphone technology, new agronomic applications were developed to reach better, cost-effective, more accurate and portable diagnosis systems. Conventional smartphones are equipped with several sensors that could be useful to support near real-time usual and advanced farming activities at a very low cost. Therefore, the development of agricultural applications based on smartphone devices has increased exponentially in the last years. However, the great potential offered by smartphone applications is still yet to be fully realized. Thus, this paper presents a literature review and an analysis of the characteristics of several mobile applications for use in smart/precision agriculture available on the market or developed at research level. This will contribute to provide to farmers an overview of the applications type that exist, what features they provide and a comparison between them. Also, this paper is an important resource to help researchers and applications developers to understand the limitations of existing tools and where new contributions can be performed.
\end{abstract}

Keywords: precision agriculture; mobile applications; mobile computing; smartphone-based apps; machine learning; visual inspection

\section{Introduction}

Increasingly, farmers realize that Information and Communications Technologies (ICT), with their potential to transform the nature of work and the structure of the workplace, are no longer a futuristic nicety, but a current reality [1].

The smartphones powered by novel sensing technologies, artificial intelligence (AI) and machine learning (ML) algorithms create a new intelligent intermediary layer between people and systems to solve efficiently complex problems or, even, to address many daily problems. In fact, for the year 2018, intelligent applications were identified in the top-ten (second place) strategic technology trends globally [2]. More and more users want to be connected to useful data and information in real-time. For this reason, the use of mobile communications has increased exponentially in the last 5 years. According to Statista [3], in 2017, 195 billion of mobile applications were downloaded by consumers and by 2021 it is expected that this number grows to about 350 billion. 
Despite the enormous potential for applied mobile technologies in agriculture, there is yet a slow adoption in the use of this technology compared to other business domains. However, the concept of mobility has being valued and adopted due to the recognition of the mobile applications' potential. The need for new platforms to help and facilitate the tasks of farmers is growing and becoming an indispensable tool at personal, social and professional levels [4].

The data collected in precision agriculture may appear in different formats, with specific content and heterogeneous structures. For this reason, it is an added value to develop systems to which the farmer can directly and intuitively access [5]. Mobile applications allow allocating all different information in one place that farmers can access. From there, the farmers can get crop maps, monitor their crops in real-time, receive alerts and perform tasks. All this in the "palm of their hands" and even if they are miles away from the crops [6].

\subsection{Role of ICT, Smartphones and Mobile Applications in Agriculture}

The unavoidable importance of ICT and their application in precision agriculture has created a new concept called e-Agriculture, which focuses on improving agricultural development through the use of various technologies [7].

E-Agriculture may involve the use of techniques such as GIS, remote sensing, and wireless devices that require access to PCs and/or the Internet and/or mobile devices. The use of mobile communication technologies (MCT) brings us to another sub-concept of e-Agriculture, called m-Agriculture. MCT include all types of handheld devices, such as basic mobile phones, smartphones, or tablets. m-Agriculture may involve the collection of remote data, such as data from automated weather stations (AWS) or from systems and sensors used in location-based monitoring [8]. This fact represents an ongoing and growing challenge to design and develop new technology strategies that enable farmers to access data and use it as specific information for better decision making [7].

Nowadays, farmers have a great need for information from crop planning to final product sales (Figure 1). This information varies according to the crop calendar, however, there are some categories of information that are common to different epochs and independent of the crop type and its location [9]. These categories are divided into three main stages-know-how; contextual information; and market information.

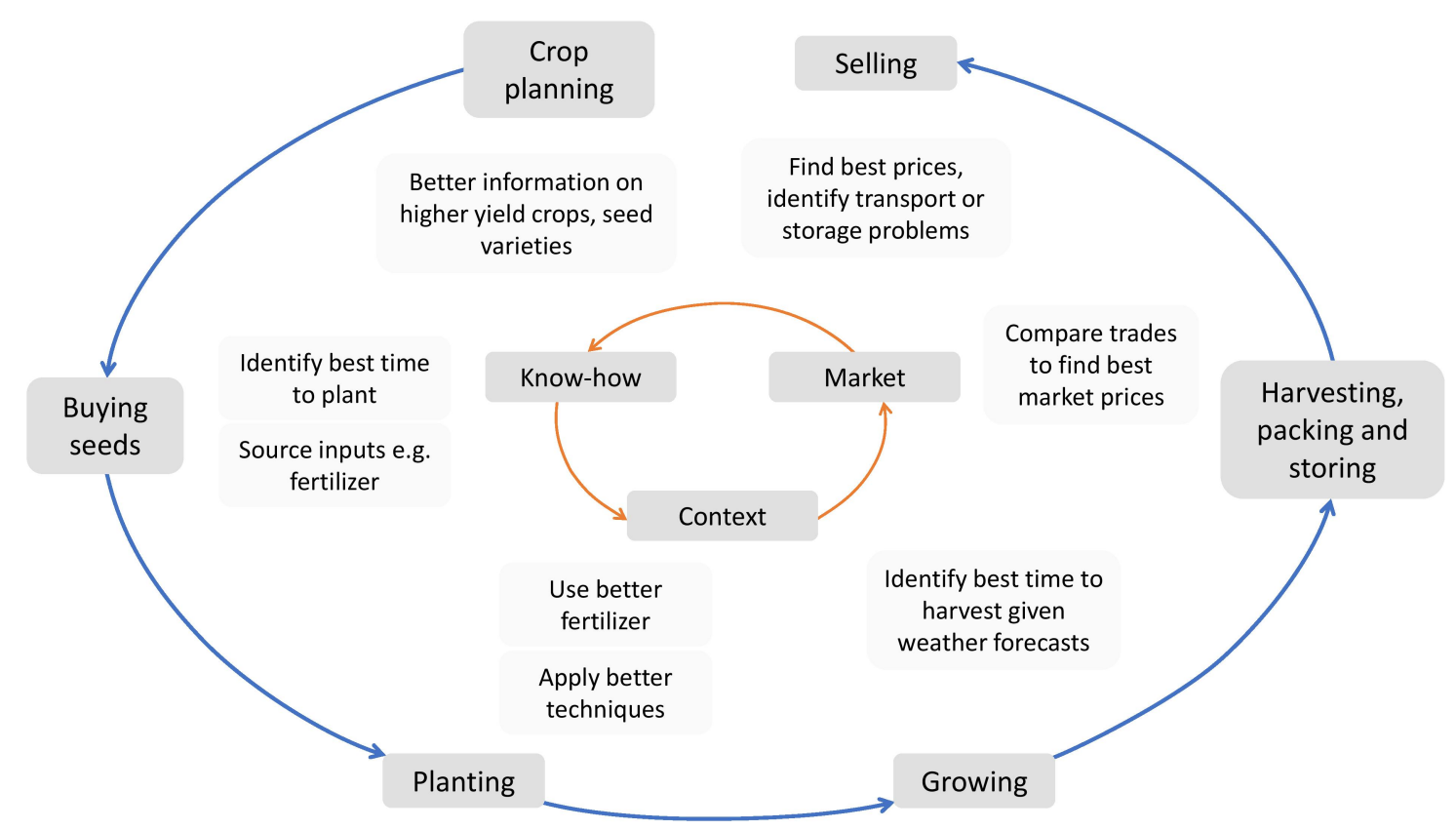

Figure 1. Information needed from farmers through the agricultural cycle (Adapted from Reference [9]). 
There is also a number of key questions posed by farmers at each stage that must be answered for better production. These questions are presented in Table 1.

Table 1. Information that the farmer needs at each stage [9].

\begin{tabular}{ll}
\hline Stage & Typical Information Needed \\
\hline \multirow{2}{*}{ Know-how } & $\begin{array}{l}\text { What are the new crop options? } \\
\text { Are there higher value crops that I can grow? }\end{array}$ \\
\hline \multirow{2}{*}{$\begin{array}{l}\text { Contextual } \\
\text { information }\end{array}$} & $\begin{array}{l}\text { When/how much should I sow? } \\
\text { When should I harvest taking climate/soil into account? } \\
\text { What are the best practices for my crop/soil? }\end{array}$ \\
\hline information & What are the products prices? \\
\hline
\end{tabular}

The use of ICT can play a key role in agriculture [10] as they allow to improve the production chains, the management and marketing of the production, as well as the management of land and its natural resources [1]. The role of ICT in agriculture can be summarized as follows [11]:

"[...] it may be safely stated that modern large scale farming technology [...] controlled by state of the art information and communication technology has the potential for substantial reductions of the production costs for agricultural commodities."

\subsection{Mobile Ecosystems}

Mobile ecosystems consist of a set of goods and services offered by a mobile device company, including hardware, operating system and applications store [12]. Within the hardware category can be placed various types of mobile devices and all the physical components that constitute them. One of the main types of mobile devices used nowadays are smartphones.

A smartphone is a mobile phone that allows to make more than just phone calls and send text messages. Smartphones have features that are present on personal computers allowing the user to surf the Internet, use multimedia features (such as music, video, camera, or gaming). Also, other advanced features can be added through additional software run by the operating system. These software are commonly known as mobile applications. There are thousands of applications for various purposes, including games, productivity, entertainment, education, among others. Today's smartphones have several modems that support various wireless communications protocols (such as Wi-Fi, Bluetooth, NFC, or satellite navigation) and they are also equipped with numerous sensors (such as gyroscope, accelerometer, temperature, or pressure). A complete list and an in-depth look at these modems and sensors are provided in Section 1.3 of this paper.

There are currently two major smartphone operating systems: Android developed by Google (Mountain View, CA, USA) and iOS developed by Apple (Cupertino, CA, USA). There was also a third operating system developed by Microsoft (Redmond, WA, USA) initially called Windows Phone and later replaced by Windows 10 Mobile. However, support for this operating system ended in December 2019. In this way, a brief description of the current two major mobile operating systems will be given.

Android is a mobile operating system based on a modified version of the Linux kernel and other open-source software. Since it is a cross-platform operating system, it currently equips most smartphones. The first version of Android appeared in September 2008 and recently (September 2019) was released the version 10.0 (Android 10). Android has an application store named Google Play that offers free and paid applications. According to Statista [13], in the third quarter of 2019 there were about 2.5 million applications in the Google Play, $96.2 \%$ free and $3.8 \%$ paid [14].

iOS is a mobile operating system designed only for Apple devices, as Apple does not allow this operating system to run on third party hardware. The first version of iOS appeared in June 2007 and recently (December 2019) was released version 13.3 (iOS 13). iOS has an application store named App 
Store which offers, like Google Play, free and paid applications. According to Statista [13] in the third quarter of 2019 there were about 1.8 million applications on the App Store, 90.8\% being free and 9.2\% paid [14].

\subsection{Smartphone Embedded Sensors/Modems and Their Functionalities}

The connectivity modems [15] and the various built-in sensors [16] enhance the smartphone ability to assist the user in performing numerous tasks. In particular, for tasks related to precision agriculture practices, they can be divided into five main categories: motion sensors; image sensors; environment sensors; position sensors and connectivity modems. The main sensors or connectivity modems that constitute each of these categories, as well as their functionality and applicability in agricultural practices, are presented in Table 2. Other sensors/modems that sometimes equip smartphones but have no use for agricultural-related applications were left out of this table.

\subsection{Smartphone Applications for Agriculture}

Aiming to merge agricultural knowledge with digital technology, a variety of smartphone applications have been developed according to farmers' needs which can be grouped into the following categories [17]: agriculture management information; agriculture information resource; agriculture calculator; agriculture news; weather; and m-government. Besides, Reference [5] also presents the following categories: learning and reference; diseases and pests; market data; conference; business; and field mapping.

In this work, the smartphone agricultural applications are categorized based on the agricultural sub-system where they are used. That resulted in three main categories: crop operations; farm management; and information system. The crop operation category includes decision making support at the crop system level, such as-crop protection and diagnosis; crop nutrition and fertilization; crop irrigation; crop growth and canopy management; and crop harvest. The farm management category includes applications that help farmers to manage more efficiently and effectively farm resources (farm system), such as: field mapping and soil information; machinery management; and control of farm activities. Finally, the information system category includes applications that provide farmers with essential information at the agricultural system level, such as: agricultural tips and knowledge; market information; relevant news; chat with experts; and climate information.

In summary, this paper reviews recent advances and developments in the field of smartphonebased agricultural technologies. It is provided a literature review and a systematic analysis of the characteristics and functionalities of various mobile applications that have been developed for use in smart/precision agriculture. These are available on the market or developed as part of an investigation. Several types of applications will be included, being divided into categories. These range from simple farm management applications to advanced decision-making applications with data processing algorithms built on the smartphone itself or in the cloud, such as the tool/platform described in Reference [18].

There are some published reviews of agriculturally oriented mobile applications, such as Reference [19]. However, that is a limited review where only four applications are addressed and a superficial description about each of them is made. In Reference [8] several applications are presented, being most of them web-based and not developed exclusively for mobile devices. Besides, they present only 4 applications for Android devices that were published before 2011. In Reference [5] another review is presented limited to applications developed for the Android platform and only a superficial description of each is presented. In Reference [20], a review of smartphone-based sensors applications in agriculture is made by 2014. However, many of them are designed for very specific tasks, not presenting great utility to farmers in general. In this way, this paper brings a state-of-the-art update of this topic, presenting applications not covered in other studies and a more in-depth analysis of recently (post-2012) developed and available applications. 
Table 2. Main built-in smartphone sensors and connectivity modems.

\begin{tabular}{|c|c|c|}
\hline Smartphone Sensors and Modems & General Function & $\begin{array}{l}\text { Application in Agricultural } \\
\text { Practices }\end{array}$ \\
\hline \multicolumn{3}{|l|}{ Motion sensors } \\
\hline Accelerometer & $\begin{array}{l}\text { Measure rotational velocity along } \\
\text { the Roll, Pitch, and Yaw axes }\end{array}$ & $\begin{array}{l}\text { Motion detection (shake, tilt, etc.) to } \\
\text { assist in the agricultural machine's } \\
\text { navigation }\end{array}$ \\
\hline Gyroscope & $\begin{array}{l}\text { Measure orientation and angular } \\
\text { velocity }\end{array}$ & $\begin{array}{l}\text { Rotation detection (spin, turn, etc.) } \\
\text { to assist in the agricultural } \\
\text { machine's navigation }\end{array}$ \\
\hline Magnetometer & $\begin{array}{l}\text { Measure direction, strength, or } \\
\text { relative change of a magnetic field }\end{array}$ & $\begin{array}{l}\text { Create a compass to assist in the } \\
\text { agricultural machine's navigation }\end{array}$ \\
\hline \multicolumn{3}{|l|}{ Image sensors } \\
\hline Camera & Record images and videos & $\begin{array}{l}\text { Image processing for objects } \\
\text { characterization and counting }\end{array}$ \\
\hline \multicolumn{3}{|l|}{ Environment sensors } \\
\hline Temperature & Measure the ambient temperature & $\begin{array}{l}\text { Measure the ambient temperature in } \\
\text { the field to be used, for example, by } \\
\text { growth, climate and pest models }\end{array}$ \\
\hline Relative Humidity & $\begin{array}{l}\text { Measure the ambient relative } \\
\text { humidity }\end{array}$ & $\begin{array}{l}\text { Measure the ambient relative } \\
\text { humidity in the field to be used, for } \\
\text { example, by growth, climate and } \\
\text { pest models }\end{array}$ \\
\hline Pressure & Measure the ambient pressure & $\begin{array}{l}\text { Measure the ambient pressure in the } \\
\text { field to calculate altitude, for } \\
\text { example }\end{array}$ \\
\hline Light & Measure ambient illuminance in lux & $\begin{array}{l}\text { Measure ambient illuminance in the } \\
\text { field to correct image colors, for } \\
\text { example }\end{array}$ \\
\hline \multicolumn{3}{|l|}{ Position sensors } \\
\hline $\begin{array}{l}\text { Global Navigation Satellite } \\
\text { System (GNSS) }\end{array}$ & $\begin{array}{l}\text { Provide geolocation and time } \\
\text { information }\end{array}$ & $\begin{array}{l}\text { Geolocation of samples taken in the } \\
\text { field and agricultural machines } \\
\text { navigation }\end{array}$ \\
\hline \multicolumn{3}{|l|}{ Connectivity modems } \\
\hline Cellular network & $\begin{array}{l}\text { Allow connection to a cellular } \\
\text { network }\end{array}$ & $\begin{array}{l}\text { Communicate with a remote server } \\
\text { to send data and/or receive } \\
\text { information resulting from its } \\
\text { processing }\end{array}$ \\
\hline $\mathrm{WiFi}$ & $\begin{array}{l}\text { Create wireless local area } \\
\text { networking (WLAN) of devices }\end{array}$ & $\begin{array}{l}\text { Communicate with devices that } \\
\text { may be scattered across the field } \\
\text { and communicate with a remote } \\
\text { server to send data and/or receive } \\
\text { information resulting from its } \\
\text { processing }\end{array}$ \\
\hline Bluetooth & $\begin{array}{l}\text { Exchange data between fixed and } \\
\text { mobile devices over short distances }\end{array}$ & $\begin{array}{l}\text { Communicate with devices that } \\
\text { may be scattered across the field }\end{array}$ \\
\hline Near Field Communication (NFC) & $\begin{array}{l}\text { Enable wireless information } \\
\text { exchange between nearby devices }\end{array}$ & $\begin{array}{l}\text { Read information of tags distributed } \\
\text { across fields }\end{array}$ \\
\hline
\end{tabular}

In this paper, Section 2 presents the materials and methods used in this review, namely the data sources, the application categories, the filtering criteria, and the information that will be presented for each of the applications. Section 3 presents the research results, that is, the applications addressed in this review, Section 4 presents a discussion and critical analysis of this research, and Section 5 presents the conclusions of this work, making reference to the challenges imposed during process of observing and analyzing the applications, to the limitations of the applications addressed in this research and providing information on future advances and trends. 


\section{Material and Methods}

\subsection{Data Sources}

This systematic review collects the latest developments in smartphone-based agricultural applications reported from 2012, inclusive, to the present. The bibliography has been built upon searches in the Scopus, Web of Science, ScienceDirect and IEEE Xplore Digital Library databases. Reference list of included articles/papers and relevant review articles/papers were examined to identify every study in which the electronic search strategy may be missed. This review also includes applications available in the Google Play, which offers free and paid applications developed for the Android platform and App Store, which offers free and paid applications developed for the Apple platform. The search queries included the following terms: (mobile OR smartphone OR smartphone-based OR cellphone) AND (app OR application) AND (agriculture OR precision agriculture) AND (android OR ios).

\subsection{Groups of Agricultural Applications}

The applications are grouped according to the three main categories and their subcategories presented in Section 1.4. The types of applications that fall into each of the categories are as follows:

1. Crop operations:

(a) Crop protection and diagnosis:

- Pest and diseases detection and diagnosis;

- Weeds identification and treatment;

- Soil and plant diagnosis.

(b) Crop nutrition and fertilization:

- Crop nutrition monitoring;

- $\quad$ Spraying management;

- Fertilization application.

(c) Crop irrigation:

- Crop hydric status and irrigation decision;

- Support irrigation.

(d) Crop growth and canopy management:

- Track canopy growth;

- Calculate LAI (Leaf Area Index).

(e) Crop harvest:

- Estimation of productivity;

- Indicators of quality.

2. Farm management:

(a) Field mapping and soil information:

- Field location and area calculation;

- Identification of sample collection points;

- Soils agricultural indicators: colour, $\mathrm{pH}, \mathrm{NPK}(\mathrm{N}$-nitrogen, $\mathrm{P}$-phosphorus and $\mathrm{K}$-potassium), carbon content, etc.

(b) Machinery management:

- Machinery costs estimator; 
- Real-time field trajectories monitoring;

- Machinery monitoring: activities, productivity, efficient use, stability, etc.

(c) Control of farm activities:

- Manage field tasks;

- Manage farm workers' activities.

3. Information system:

- Agricultural tips and knowledge;

- Market information;

- Relevant news;

- Chat with experts;

- Climate.

Some of the applications, due to the varied number of features, fall into more than one subcategory. In this case, they were placed in the subcategory corresponding to their main functionality/purpose.

\subsection{Filtering Criteria}

Five main applications' exclusion criteria have been defined. These criteria are as follows:

- Applications not relevant to agriculture;

- Applications for non-plant-based agriculture (e.g., livestock, aquaculture, poultry farming, etc.);

- Applications that communicate with a remote terminal only to monitor sensors (e.g., weather stations);

- Web-based applications that cannot be installed on mobile devices (e.g., applications that run in the web browser);

- Applications that do not provide the English language.

This systematic review includes applications published in scientific documents and applications available on Google Play and/or the App Store. Therefore, the research process related to filter results is very challenging, because hundreds of applications can fit in each category. For that reason, two more exclusion criteria were defined to be applied only to the applications found through the Google Play and/or App Store:

- Applications found on Google Play and/or App Store rated less than 3.5 stars (if available in both stores, must be less than 3.5 in both) on the date of this review (May 2020);

- $\quad$ Paid applications found on Google Play and/or App Store.

\subsection{Information Displayed}

For each of the smartphone applications covered in this paper, a brief description will be presented, clearly indicating its purpose and its main features. Also, illustrative images of their interfaces are showed. At the end, a comparative table that summarizes the main characteristics of each of the applications is presented. These characteristics are:

- Type of application (crop protection and diagnosis; crop nutrition and fertilization; crop irrigation; crop growth and canopy management; crop harvest; field mapping and soil information; machinery management; control of farm activities; information system);

- $\quad$ Processing type (without processing; local processing; cloud processing);

- Operating platform (Android; iOS; Windows 10 Mobile) and source from which the application was found (scientific database; Google Play; App Store);

- Download availability;

- Languages in which it is available; 
- Need for the Internet connection;

- Use of internal sensors;

- Need for external sensors;

- Possibility to save and reuse data (export and import data);

- Interface (little cared; simple; elaborated) and ease of use.

\section{Results}

The various applications found throughout this search are presented here. They are grouped according to the categories previously mentioned (crop operations; farm management; and information system). For each of these applications, a brief description of it, its main features and functionalities, and an illustrative image of its interface are presented.

\subsection{Crop Operation}

This category includes applications that help farmers in general crop-related activities on their farms: crop protection and diagnosis; crop nutrition and fertilization; crop irrigation; crop growth and canopy management and crop harvest.

\subsubsection{Crop Protection and Diagnosis}

Plantix [21,22], developed by PEAT GmbH (Berlin, Germany), is a diagnosis application that detects diseases, pests, and nutritional deficiencies using an image of the plant to be analyzed. The application uses image recognition and deep learning (DL) algorithms to detect about 400 damage occurrences in 30 crop types. It also offers a list, divided by regions, with the most common diseases. The image is sent to the cloud where it is processed and a result is generated. Besides receiving the individual diagnosis, the user can also view information about conventional treatments, alternative treatment options and preventive measures. All of this information is available offline so that it can be accessed in places without network coverage. This application also allows posting the image in the Plantix community in order to get more information from other members and qualified technicians. Besides, it also allows viewing weather forecasts (temperature, precipitation, and wind speed) for the location where the user is. Figure 2 presents three screenshots of the application: the main menu, the interface where the image to be analyzed is captured and the interface where the image processing result is presented.

BioLeaf (Foliar Analysis) [23,24], developed at the Federal University of Mato Grosso do Sul (Campo Grande, Brazil), is an application that, using images captured by the smartphone or uploaded from the photo gallery, allows to identify automatically and in situ the regions of leaves with lesions caused by insects. Also, it estimates the defoliation percentage in relation to the total leaf area. This is a nondestructive identification method as it does not require the leaf to be removed from the plant. This application allows to automatically estimate the lesion area if the leaves contours were not affected. If this happens, the user must manually reconstruct the contour using curves and control points. For the application to make a correct analysis, it is necessary to place a white surface behind the leaf to be analyzed. The application was tested by the authors using soybean leaves, but preliminary experiments have shown that it is also suitable for use in different crops, such as vine leaves. Figure 3 presents three screenshots of the application: the main menu, the interface where the captured leaf image is shown and the interface where the image segmentation and processing result (defoliation percentage) are presented. 


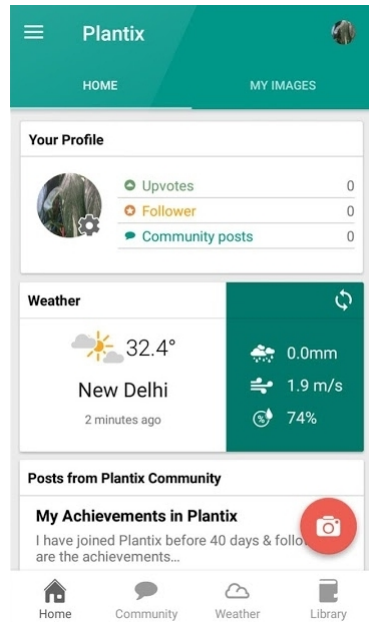

(a)

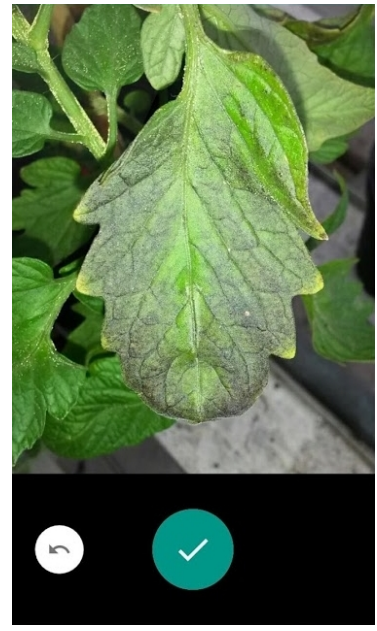

(b)

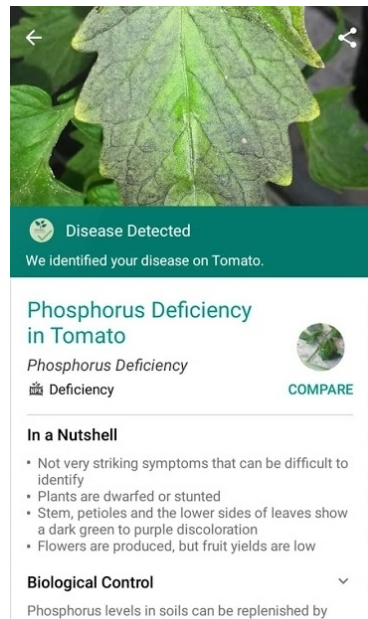

(c)

Figure 2. Plantix: (a) Main menu; (b) Capture image interface; (c) Image processing result.

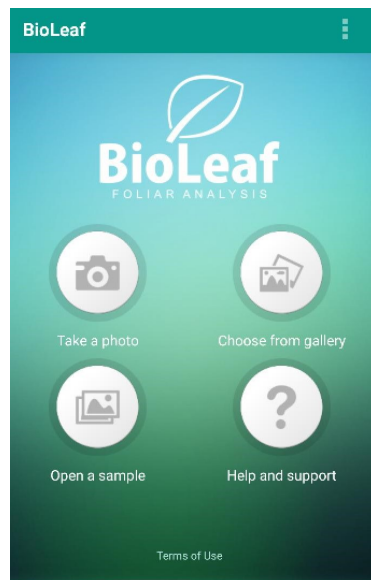

(a)

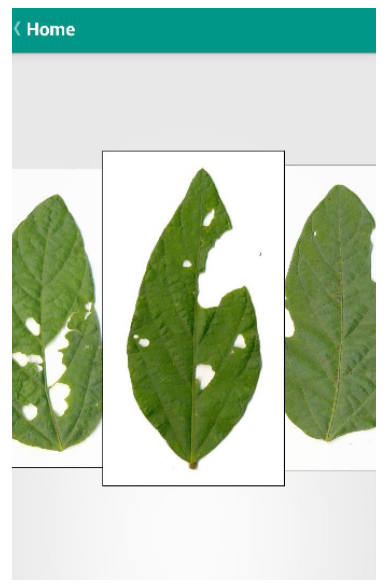

(b)

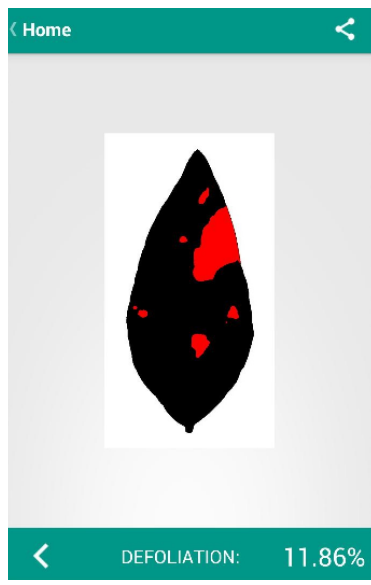

(c)

Figure 3. Bioleaf: (a) Main menu; (b) Captured leaf image; (c) Image segmentation and processing result.

E-agree [25], developed at Jaywant College of Engineering \& Management (Maharashtra, India), provides a variety of services to farmers. These include an image processing system to detect plant diseases based on their leaves, a marketplace which helps farmers sell/buy products online, and a market rate guide that helps farmers to gather information about market rates. It also provides a weather reporting system that plays a crucial role in decision making, as well as soil types information to guide farmers in deciding which crop type is the most appropriate to their fields. Figure 4 presents three screenshots of the application: the main menu, the interface where images are uploaded and diseases are checked and the interface where the weather report is presented.

ADAMA Bullseye [26], developed by ADAMA Agricultural Solutions (Tel Aviv, Israel), has a database that helps farmers identifying (by visual comparison) pests and diseases in rice, almonds, tomatoes, apple, watermelon and cotton crops. It also provides information on the life cycle of pests and diseases that can be found in the application by searching for their name or symptoms and also allows to consult weather forecasts provided by the ADAMA Climate service. If the farmer cannot identify the pest/disease, he/she can send photos of their crop for evaluation by qualified technicians. Figure 5 presents three screenshots of the application: the main menu, the interface where the pests for a particular crop (in this case apple) are presented and the interface where information about a particular disease or pest is presented. 


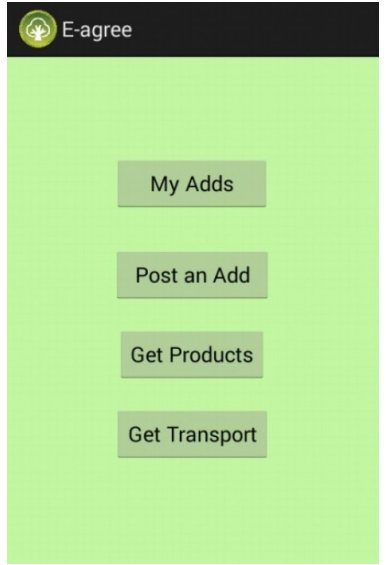

(a)

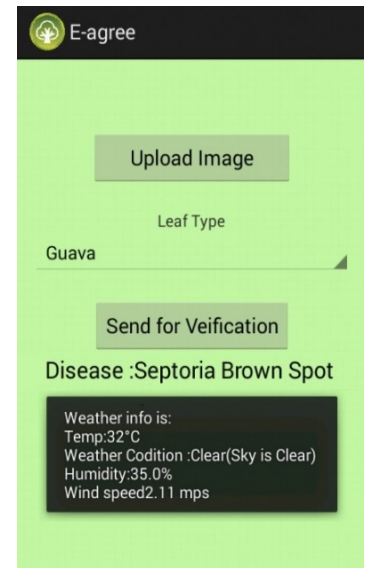

(b)

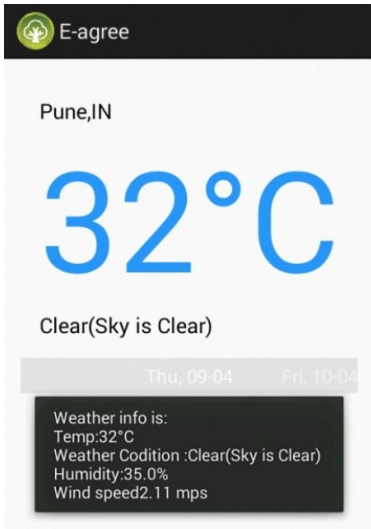

(c)

Figure 4. E-agree: (a) Main menu; (b) Image upload and verification; (c) Weather report.

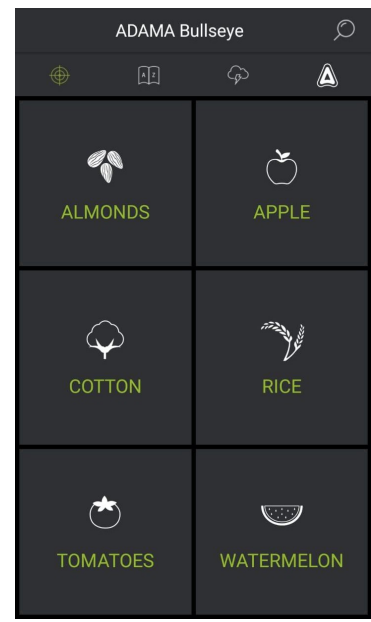

(a)

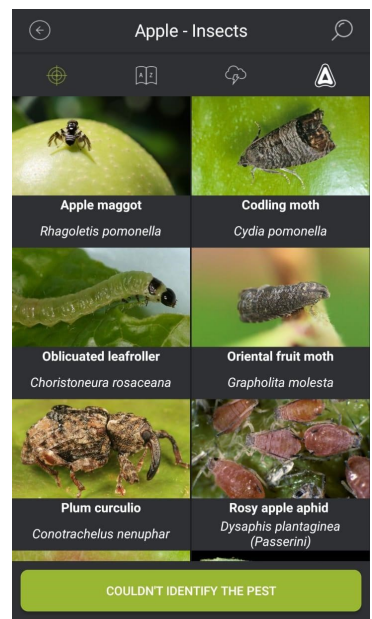

(b)

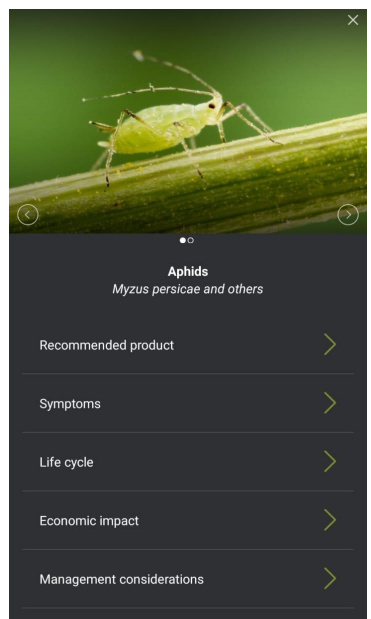

(c)

Figure 5. ADAMA Bullseye: (a) Main menu; (b) Pests of a particular crop; (c) Information about a particular pest.

PMapp $[27,28]$, developed at the University of Adelaide (Adelaide, Australia), allows users to quickly assess the powdery mildew incidence degree on grape bunches (a percentage estimate of the area covered by powdery mildew) by visually comparing it with a computer-generated image. Using a pictorial disease "key" that shows different levels of powdery mildew infection, the user can determine the proportion of affected bunches (disease incidence) and the affected area (severity). It is possible to store this data for further analysis or email them in XML or CSV format. The application also has a scoring tool (this score corresponds to the incidence and severity of powdery mildew in the field) to predict the likely impact on wine quality more accurately. Figure 6 presents three screenshots of the application: the main menu, the interface for assessing the disease incidence degree in a bunch of grapes and the data export interface. 


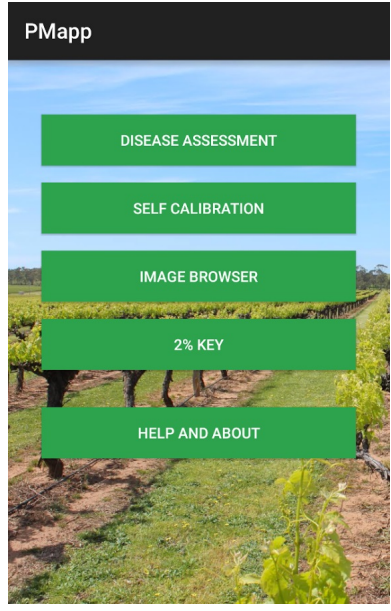

(a)

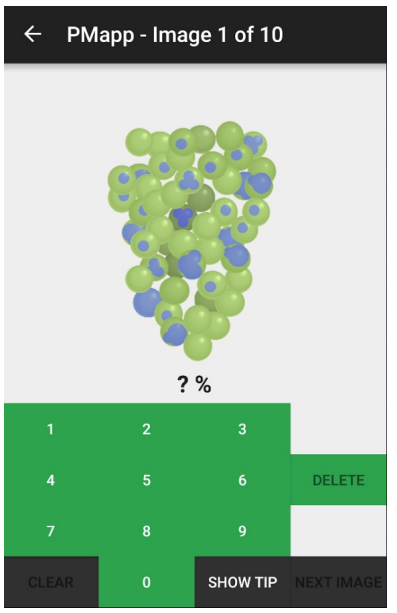

(b)

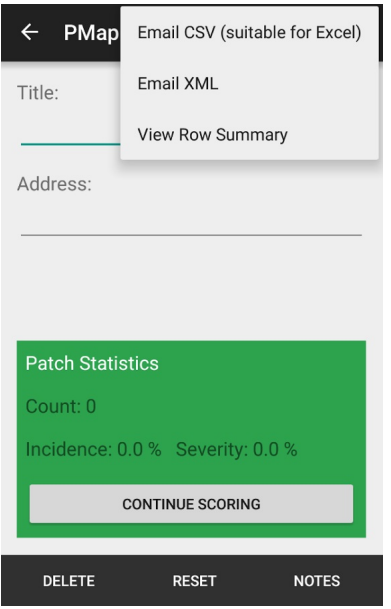

(c)

Figure 6. PMapp: (a) Main menu; (b) Assessment of the disease incidence degree in a bunch of grapes;

(c) Data export.

Plant Disease [29,30], developed at the Technological Educational Institute of Thessaly (Larissa, Greece), it allows to identify vines diseases through leaf photos with an accuracy greater than $90 \%$. The technique used for disease recognition described in this work can be performed standalone, combined with remote data (cloud) or portable molecular analysis equipment. To ensure faster image processing time and avoid background segmentation techniques, a white surface should be placed behind the leaf to be processed. The user initially chooses the photo that he/she wants to analyze, and edits the Threshold, Backgroud, and Min Spot Area values to get an image with as many valid points as possible. Then, the user can enter the type of plant, add an estimate of how many leaves are affected and when the first symptoms appeared. Weather forecasts can also be taken into account, for which it is only necessary to associate the GPS (Global Positioning System) coordinates of the place. In the end, the application presents the results with the three diseases most likely to exist. According to the authors, the application is easily adapted to other types of diseases and other operating systems. Figure 7 presents three screenshots of the application: the interface where the original image is presented, the interface where the BGW1 matrix is presented and the interface where the color histogram of the regions affected by the disease is presented.

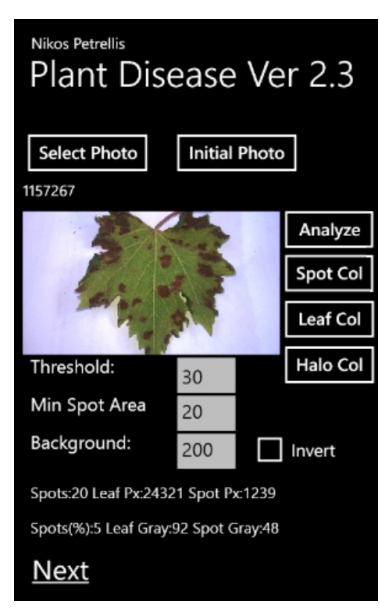

(a)

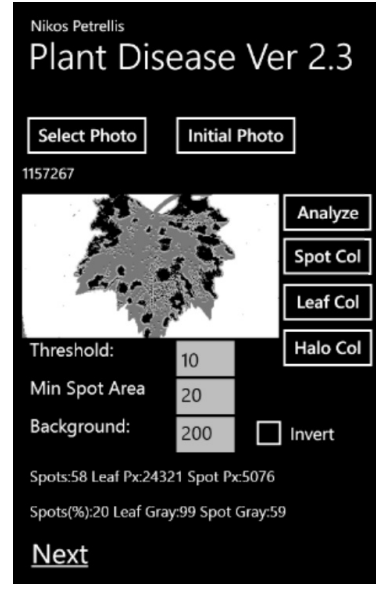

(b)

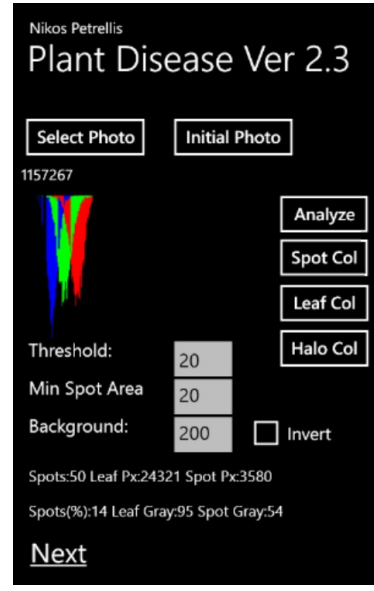

(c)

Figure 7. Plant Disease: (a) Original grape leaf photo; (b) Displaying the BGW1 matrix with Threshold equal to 10; (c) Color histogram of the regions affected by the disease. 
ImScope [31] is an experimental tool developed by Walter J., oriented to the visualization and registration of plant health indicators through image processing algorithms using a smartphone. The application uses a variety of filters and indices that are commonly used, some using the visible light captured by the smartphone camera and others trying to take advantage of a small fraction of light that can pass through the NIR filter that blocks infrared on mobile devices. This application allows to get several images, for example, NIR (near-infrared), NRG (near-infrared, red, green), NGB (near-infrared, green, blue), NDVI (normalized difference vegetation index), GRI (relative difference between green and red), GBI (relative difference between green and blue), among others. Figure 8 presents two screenshots of the application, one of them with the NDVI image and the other with the GBI image.

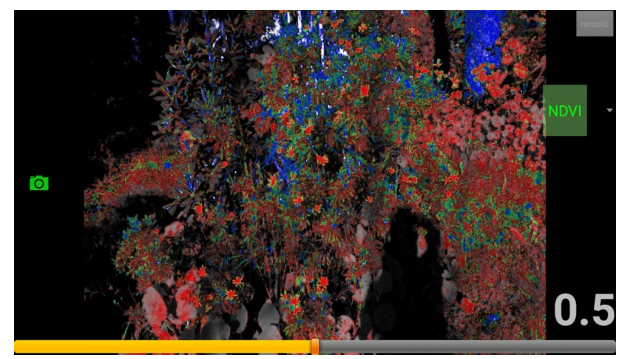

(a)

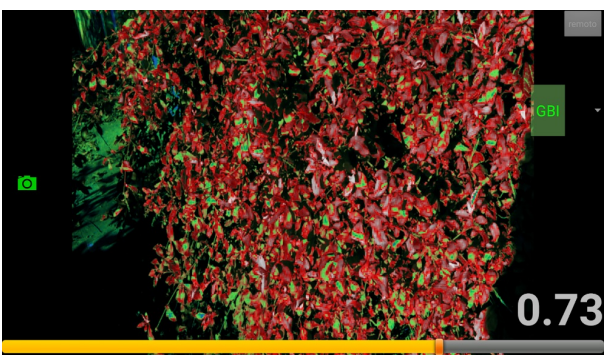

(b)

Figure 8. ImScope: (a) Normalized difference vegetation index (NDVI) image processing result; (b) GBI image processing result.

Agrobase [32] is an application developed by Farmis (Kaunas, Lithuania) that helps farmers to identify weeds, diseases or pests that arise in various types of crops and check which plant protection product (e.g., herbicides and fungicides) is most effective for each case. Authors claim that this tool enables us to increase the crop yield and reduce the use of pesticides, fungicides and herbicides. Weeds, pests and diseases can be found in the application by searching by their common name, Latin name, category, or type of crop where they are originated. The phytosanitary products can be found by searching for their active material, name, category, or type of crop where it will be applied. Figure 9 presents three screenshots of the application-the main menu, the catalog of weeds, pests and diseases and the interface where the user can view a detailed description of each one of them.

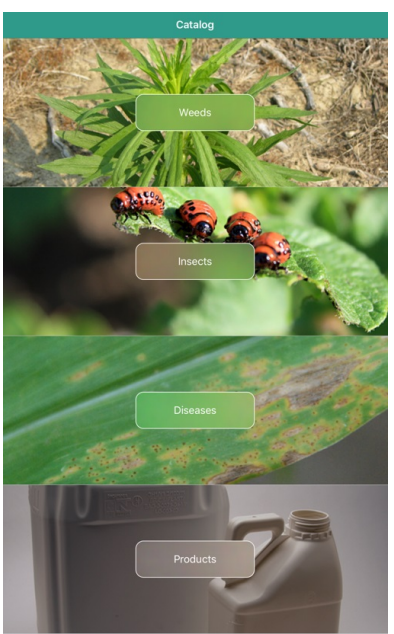

(a)

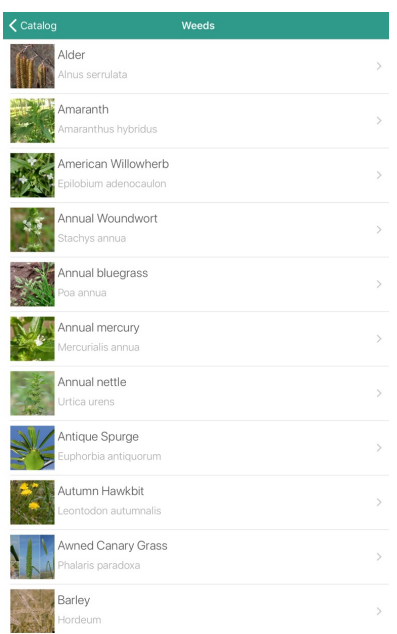

(b)

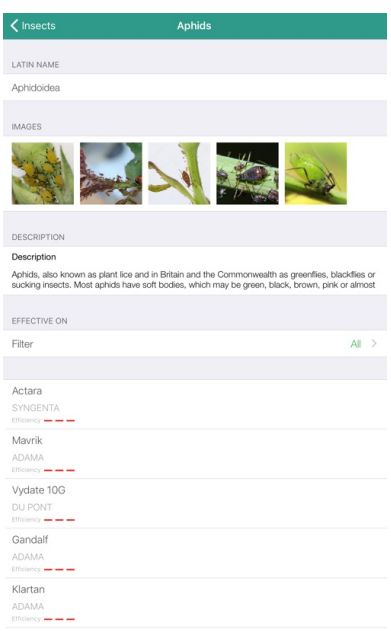

(c)

Figure 9. Agrobase: (a) Main menu; (b) Catalog of diseases and weeds; (c) Detailed description and photos of diseases and weeds. 


\subsubsection{Crop Nutrition and Fertilization}

DropLeaf [33], developed by researchers from the Federal University of Mato Grosso do Sul (Campo Grande, Brazil) and the University of São Paulo (São Paulo, Brazil), it allows the effective estimation of the coverage area of pesticide spraying. This application reads water-sensitive markers scattered in the cultivation area through an image/photo taken using a smartphone. This process consists of five steps-color space conversion; image noise removal; convolutional expansion and erosion operations; water-sensitive markers contour detection; and identification of the drops in the markers. After processing, it is possible to understand the state of pesticide coverage applied through three indicators-Coverage Density (CD); Volumetric Median Diameter (VMD); and Diameter Relative Span (DRS). Figure 10 presents three screenshots of the application: the main menu, the captured image visualization interface and the interface where the processing result is displayed.

Ag PhD Crop Nutrient Deficiencies [34], developed by Ag PhD (South Dakota, United States), helps farmers to identify nutrient deficiencies in their crops. The application provides a detailed description and photos of the various nutritional deficiencies for a wide variety of crops. The user can search for a nutritional deficiency of a specific crop by the missing nutrient type or visually through photos of crops that allow finding the image that most closely matches the fertility issue in their fields. It is, therefore, a useful tool to aid decision making in fertilization tasks. Figure 11 presents three screenshots of the application: the crop type selection menu, the menu with the list of most common nutritional deficiencies in a particular crop type and the interface where the image and description of a specific nutritional deficiency are presented.

Yara TankmixIT [35], developed by Yara International ASA (Oslo, Norway), allows verifying the physical compatibility or simulate product mixing ability in spray tanks using Yara foliar nutrition products with other spray materials. The information comes from an online database supplied in real-time with laboratory test results, and it is possible to define product quantities by simulating combinations of herbicides, fungicides and other chemicals. Once the products to be mixed are chosen, the application generates the list of all laboratory tests performed involving these same products and the results of them. If the required combination is not found, a tank mixing test can be requested. If the spray materials are available in Yara labs, a test can usually be done within a few hours. Figure 12 presents three screenshots of the application: the main menu, the Yara product choice interface and the interface where the mixing results are presented.

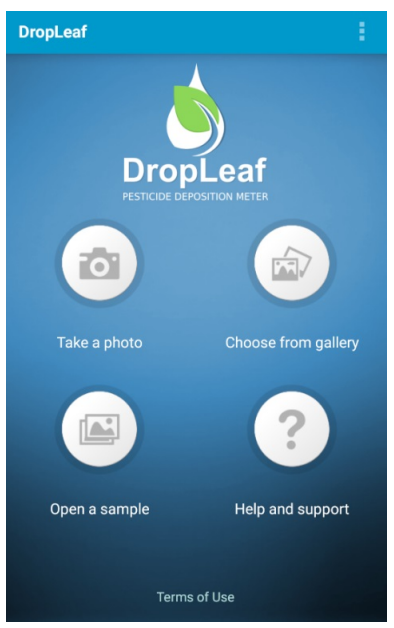

(a)

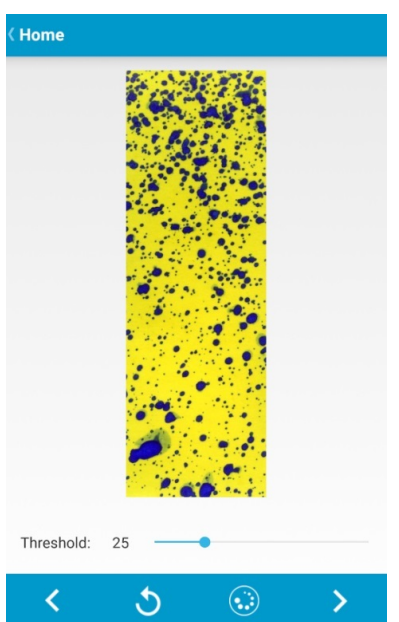

(b)

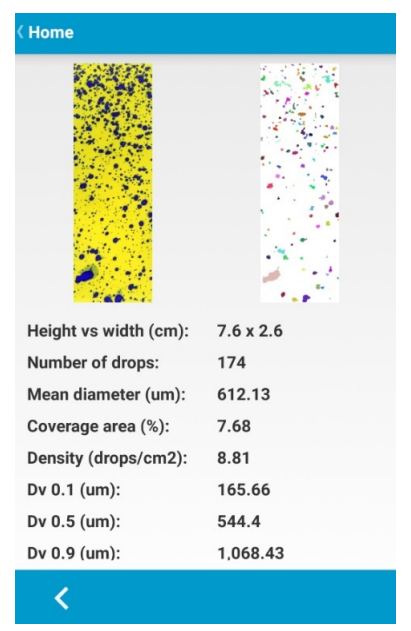

(c)

Figure 10. DropLeaf: (a) Main menu; (b) Captured image visualization; (c) Image processing result. 


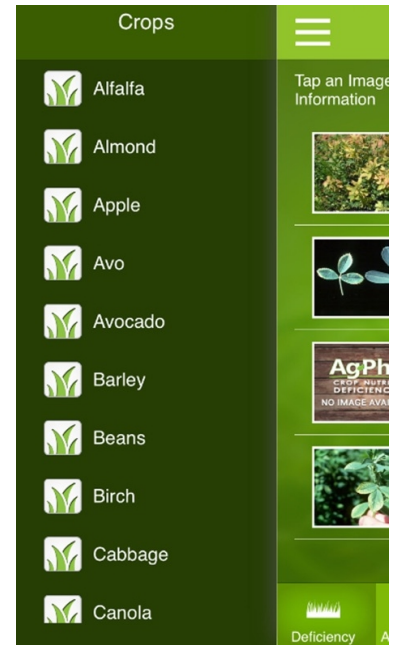

(a)

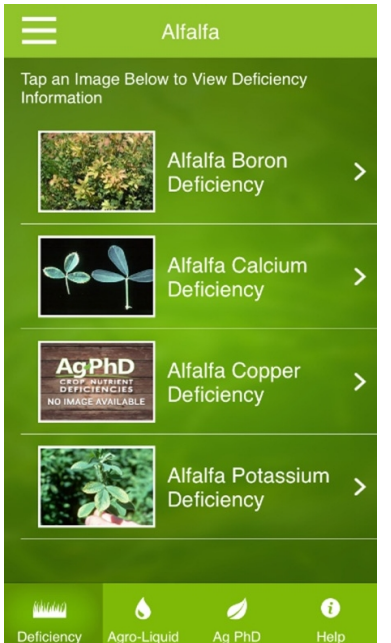

(b)

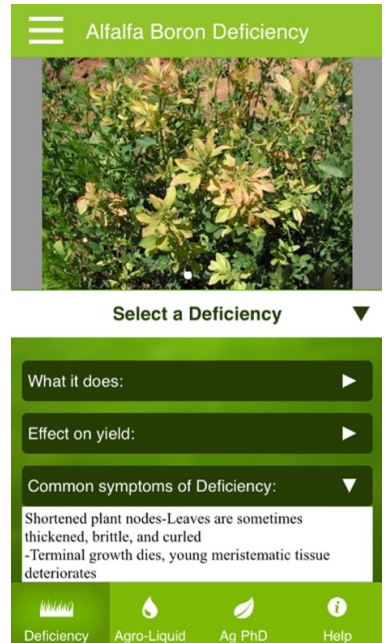

(c)

Figure 11. Crop Nutrient Deficiencies: (a) Crop type selection menu; (b) List of nutritional deficiencies; (c) Image and description of a specific nutritional deficiency.

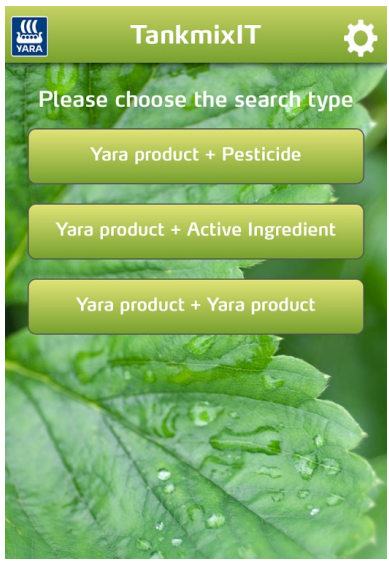

(a)

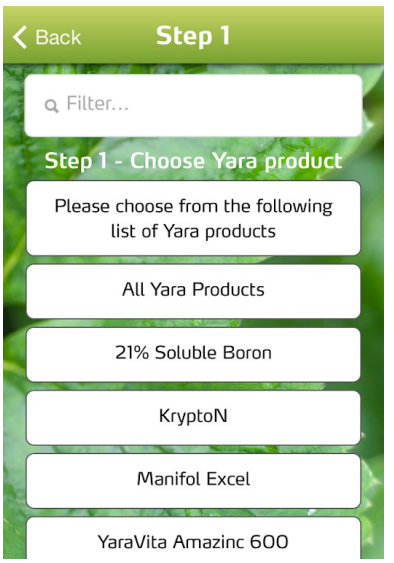

(b)

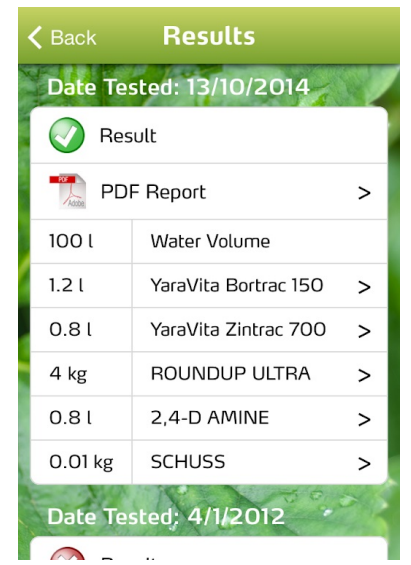

(c)

Figure 12. Yara TankmixIT: (a) Main menu; (b) Choose Yara product interface; (c) Mixing result interface.

SpraySelect [36], developed by TeeJet Technologies (Springfield, IL, United States), allows to quickly and easily choose the most suitable spray nozzle taking into account some attributes of the crop to be sprayed and the desired spray characteristics. This allows the farmers to spray their crops at the right dose. It is only necessary to enter the speed $(\mathrm{km} / \mathrm{h}$ or $\mathrm{mph})$, the spacing between the spray tips ( $\mathrm{cm}$ or in), the target rate (1/ha or gpa) and the droplet size category, and the application provides a list of recommended nozzles and useful tips. Figure 13 presents three screenshots of the application: the agricultural application type selection menu, the interface that allows setting the speed, spacing, target rate and droplet size category values, and the list of recommended nozzles.

SnapCard [37] was developed by the University of Queensland-Gatton Campus (Queensland, Australia) and the United States Department of Agriculture (USDA) Agricultural Research Service (ARS) Aerial Application Technology Research Unit in College Station (Texas, United States). It allows, like the DropLeaf application, to estimate the coverage area of pesticide spraying by reading water-sensitive markers scattered around the crop area. This application gives farmers access to a decision support tool that can be used for three purposes: compare the spray coverage obtained with the expected one, based on agronomic variables, weather conditions and spray configurations; predict spray coverage based on current conditions (time of day, tractor speed, spray nozzles, 
spray volume and weather conditions) and store spray logs locally on the device and synchronize them with the web server for later use. Figure 14 presents three screenshots of the application: the main menu, the interface where it is possible to adjust the area of interest for analysis and the interface where the processing result is presented.

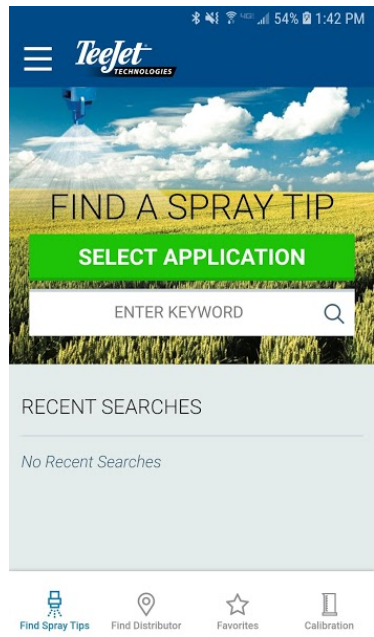

(a)

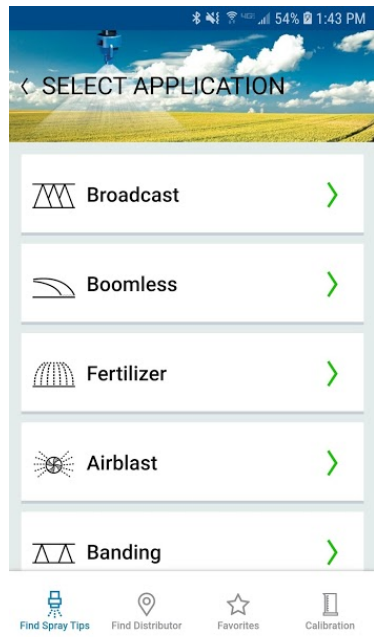

(b)

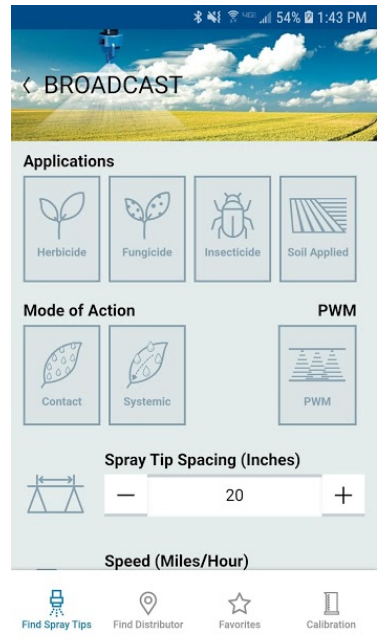

(c)

Figure 13. SpraySelect: (a) Application type selection menu; (b) Interface that allows to set the speed, spacing, target rate and droplet size category values; (c) List of recommended nozzles.

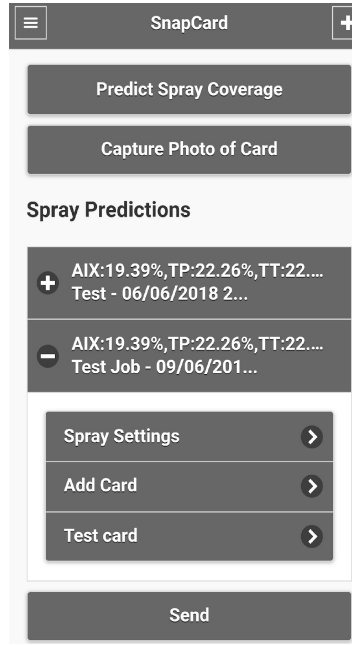

(a)

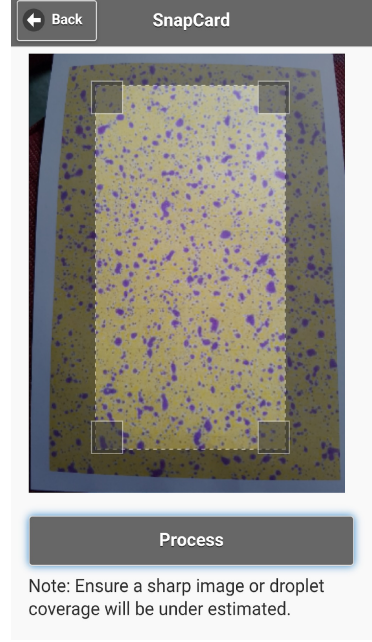

(b)

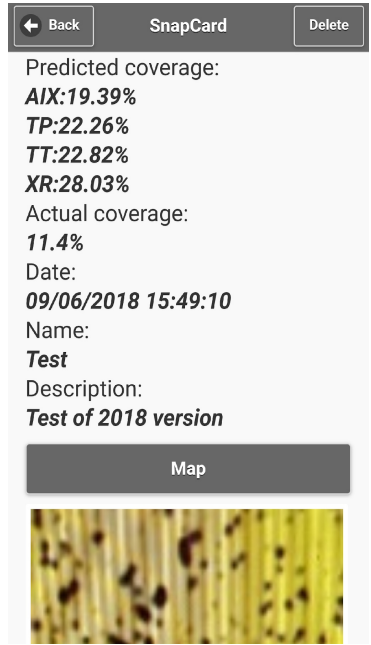

(c)

Figure 14. SnapCard: (a) Main menu; (b) Cropping tool where a scanned card is adjusted to area of interest for analysis; (c) Measured spray cover output.

EcoFert [38], developed at the Technical University of Cartagena (Cartagena, Spain), provides to the farmers the ability to calculate, via an Android mobile device, the best fertilizer mixture to get the desired nutrient solution for different crops, taking into account the current fertilizer price in the market. In order to determine which fertilizers and quantities to use, the user needs to perform the following steps: enter the data about the water composition of their irrigation systems; enter the data about the ideal solution of the crop of interest and select, from a list of fertilizers given by the application, those he/she has in stock. In case there are no fertilizers in stock, the user could select some of them from the list arbitrary or even all of them. After all data entered, the application calculates the amount ( $\mathrm{kg}$ or $\mathrm{L}$ ) of each selected fertilizer to be added to the tanks per liter of water. Finally, the user 
has the ability to save and/or email a record of the data entered and the results obtained. Figure 15 presents three screenshots of the application: the main menu, the interface where the list of fertilizers that the user can select is presented and the interface where the ideal solution to use is shown.

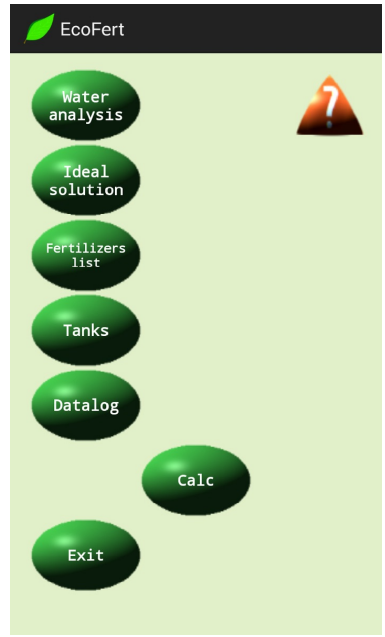

(a)

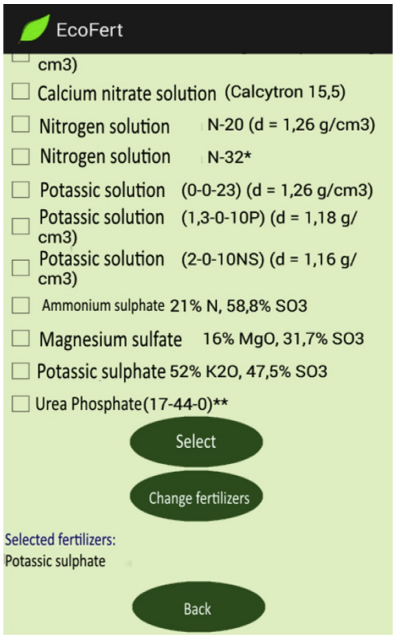

(b)

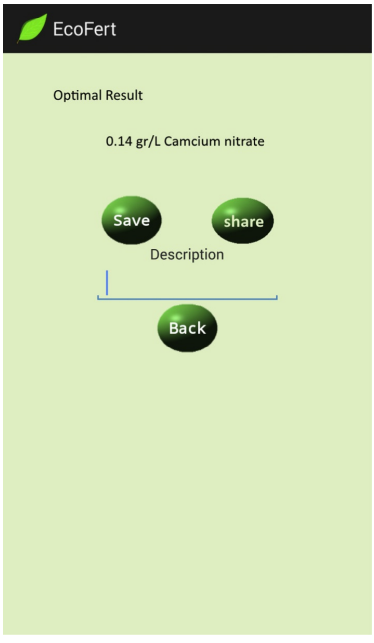

(c)

Figure 15. EcoFert: (a) Main menu; (b) Interface with list of fertilizers that user can choose; (c) Interface with the ideal solution.

Smartirrigation Cotton [39] is a mobile application for irrigation scheduling in cotton crops, developed by researchers from the University of Georgia (Georgia, United States) and the University of Florida (Florida, United States) and by Cotton Incorporated (North Carolina, United States). This application uses data from weather stations, soil parameters, crop phenology, crop coefficients and irrigation applications to estimate the root zone soil water deficits (RZSWD). As input, the Smartirrigation Cotton only requires that the user indicates the GPS coordinates of the location where he/she wants to schedule irrigation (if the user has the smartphone location enabled, the application will automatically get the current geographic location), soil type, irrigation system type and the default irrigation rate. If the RZSWD exceeds $40 \%$, phenological changes occur, or when rain is recorded at the nearest weather station, a notification is sent to the user. The model does not deliver irrigation application recommendations. However, users may utilize RZSWD information to make appropriate irrigation decisions. Figure 16 presents three screenshots of the application: the interface where the user defines the field location, the main interface of the application and an example of the notifications presented by the application.

\subsubsection{Crop Irrigation}

Grapevine water stress [40-42] is an application that is being developed by researchers at the South Australian Research and Development Institute (Adelaide, Australia) and the University of New South Wales (Sydney, Australia) and provides a portable solution to evaluate grapevine's water status. This system uses an external thermal camera (FLIR One by FLIR, Wilsonville, OR, USA) connected to a smartphone to collect canopy images from vines. The images are analyzed by the application, which estimates the water condition of the vine, allowing farmers to reduce costs in water use and optimize vineyard production. The crop water stress is calculated based on the canopy temperature relative to canopies that are well-irrigated or under severe water stress (represented by artificial reference leaves). The application was configured to automatically synchronise measurements with a server every time the phone was connected to Wi-Fi. Figure 17 presents a screenshot of the application, where the two artificial reference leaves are perfectly visible, one with large amounts of water (right circle) and the other under severe water stress (left circle). 


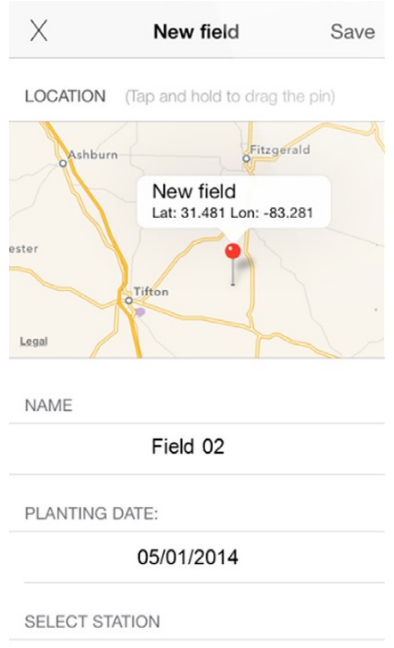

(a)

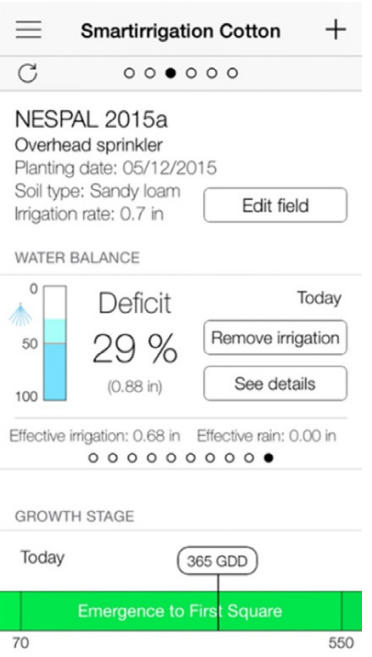

(b)

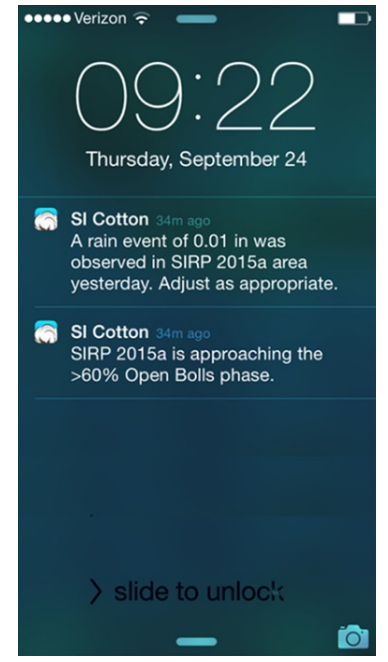

(c)

Figure 16. Smartirrigation Cotton: (a) Pin field location on map; (b) Main user-interface screen; (c) Notifications about rain and phenology change.

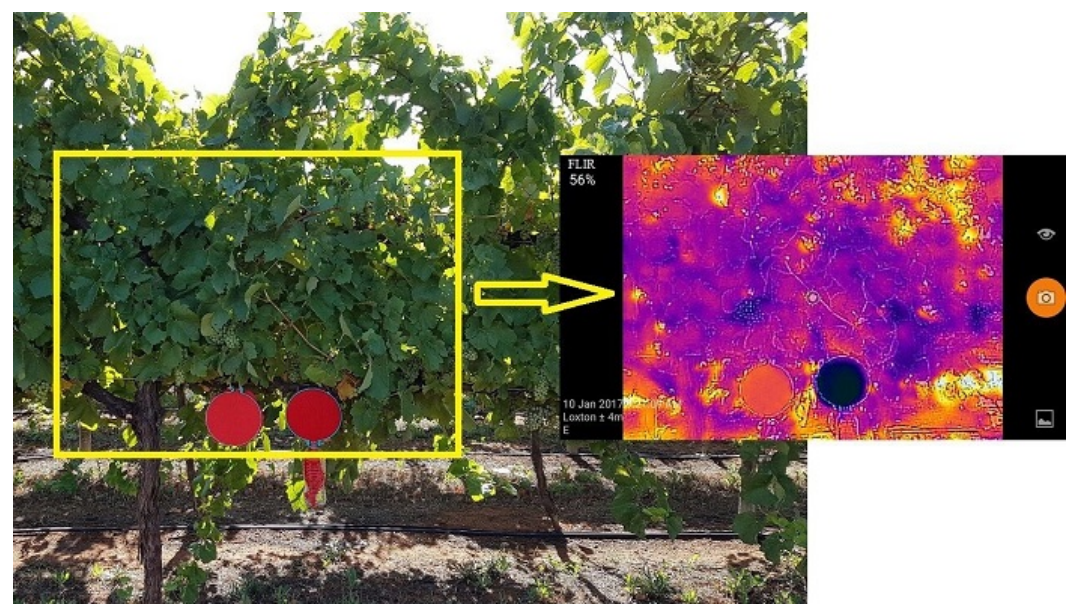

Figure 17. Grapevine water stress: Image of vines and respective thermal image.

pCAPS (portable Classification Application for Plants and Soil) [43], developed by researchers from the Autonomous University of Guerrero (Chilpancingo de los Bravo, Mexico), University of Murcia (Murcia, Spain), Technical University of Cartagena (Cartagena, Spain) and Miguel Hernández University of Elche (Elche, Spain), integrates various computer vision techniques and allows to automate the monitoring, segmentation and analysis of agricultural images. This tool allows real-time crop monitoring, providing information that can be used to automate and optimize the calculation of water needs. The processing techniques used in the application are based on the research described in Reference [44], where a new algorithm for the selection of the ideal color space for the plant/soil segmentation problem was proposed. Using the pCAPS application, the users can take pictures of their crops using the smartphone camera, automatically crop the images and perform a vegetation analysis, obtaining the percentage of green cover (PGC), number of plants, date, time, and GPS coordinates. The system is designed for easy use by unskilled users and it allows to send information via email to qualified technicians to advise the appropriate decisions to make. Figure 18 presents three screenshots of the application: the interface where the captured image is presented, the interface where the processing result is shown and the interface of the analyzed images history. 


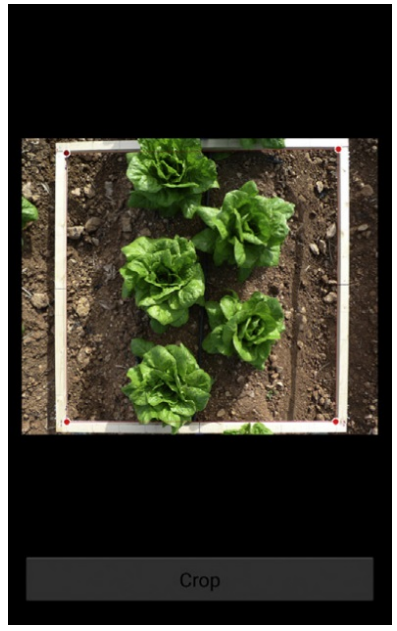

(a)

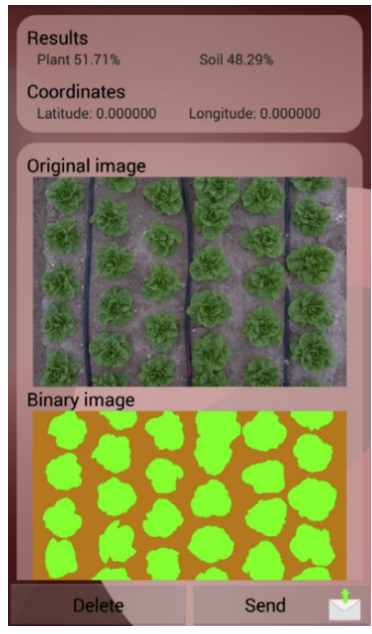

(b)

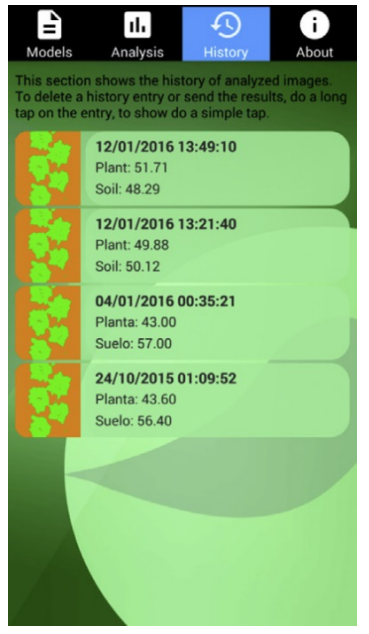

(c)

Figure 18. pCAPS: (a) Captured image visualization interface; (b) Image processing result; (c) History of analyzed images.

EVAPO [45], developed at São Paulo State University (São Paulo, Brazil), it allows real-time potential evapotranspiration (PET) estimation using data from the NASA Prediction Of Worldwide Energy Resources (NASA-POWER) system. With the help of this application, farmers can perform more efficient irrigation, allowing to increase water conservation. This application uses weather data to calculate PET using the Penman-Monteith method. To evaluate the performance of the proposed approach, the authors compared the estimated PET using the EVAPO application with that estimated from conventional surface weather station climate data. As input, the EVAPO application only requires that the user indicates the GPS coordinates of the location where he/she wants to calculate PET. If the user has the smartphone location enabled, the application will automatically get the current geographic location. The application also provides a "History" tab where the last 50 PET values obtained are displayed. Figure 19 presents three screenshots of the application: the tab that shows the PET value obtained, the measurements history tab and the application information tab.

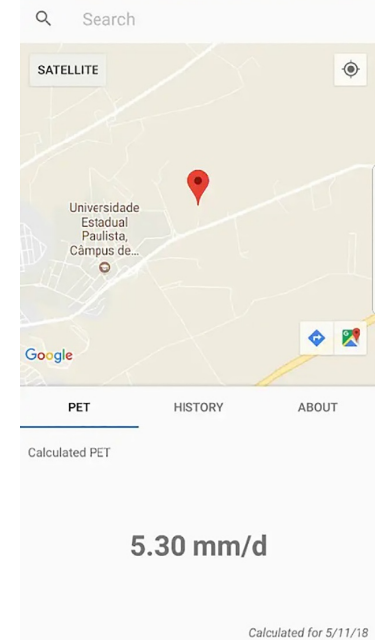

(a)

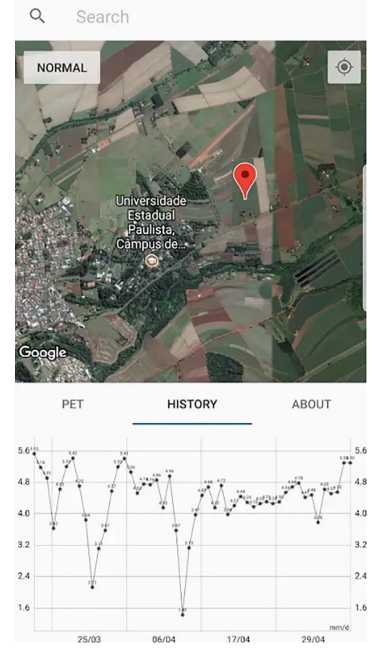

(b)

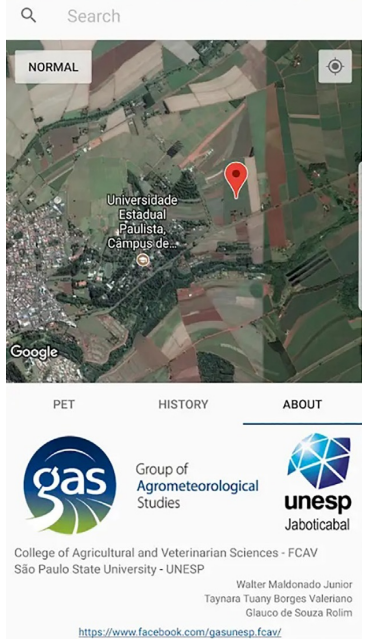

(c)

Figure 19. EVAPO: (a) "PET" tab with value obtained; (b) "History" tab with a time series of 50 past values of PET; (c) "About" tab with information about application. 


\subsubsection{Crop Growth and Canopy Management}

VitiCanopy [46-48], is an application developed by a team of researchers from the University of Adelaide (Adelaide, Australia) and the University of Melbourne (Melbourne, Australia), which allows winegrowers to take crop images (using their smartphone camera) in order to characterize the architecture (size and density) of canopy, the leaf area index of their vines, among other parameters. These parameters allow monitoring canopy growth and porosity to assess vigor, water requirements and sunlight transmission to the fruit zone, which are essential information for obtaining grape quality attributes. The application also allows associating this data with a vineyard location using smartphone GPS and GIS (Geographic Information System) techniques. Winegrowers will be able to quickly and reliably assess spatial and temporal growth and canopy architecture dynamics to manage the balance between vegetative growth and fruit yield. This application has the advantage that it can be applied not only to vineyards but also to a variety of other crops and trees such as apple trees, olive trees, among others. Figure 20 presents three screenshots of the application-the main menu, the interface where the image to be processed is selected and the interface where the parameters resulting from the image processing are presented.

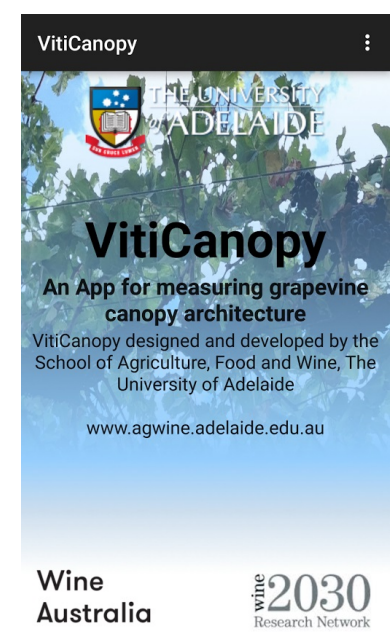

(a)

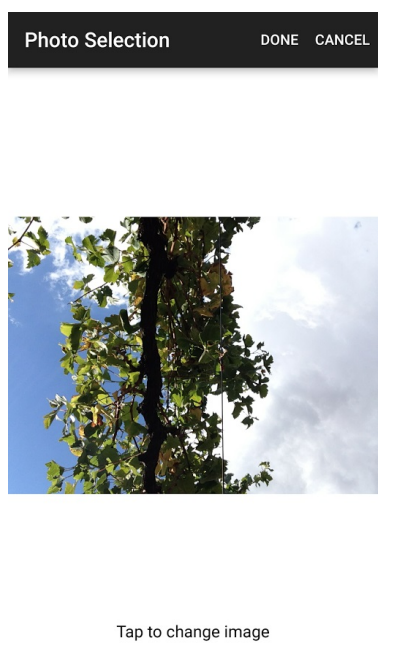

(b)

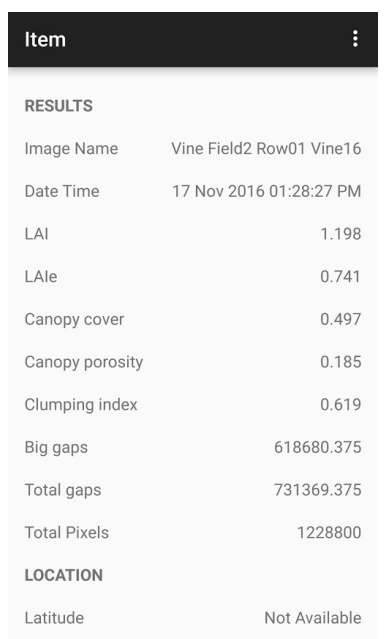

(c)

Figure 20. VitiCanopy: (a) Main menu; (b) Image setection; (c) Image processing resulting parameters.

Easy Leaf Area [49] is an open-source application [50] developed by researchers from the Department of Plant Sciences of the University of California (California, United States) that allows measuring leaf area in digital images quickly. The application uses the RGB value of each pixel to identify the regions that belong to the leaves and it is possible to measure multiple leaves in the same image. It is necessary to use a red color reference scale, with known real area, so that the application can correctly calculate the area of the leaves in the image. The scale and leaves should be placed at the same distance and parallel to the camera. Using sliders, adjustments can be made to identify the scale and leaves correctly. Figure 21 presents two screenshots of the application: the interface that allows adjusting the parameters to detect the scale and leaves correctly and the interface where the image processing result is displayed. 


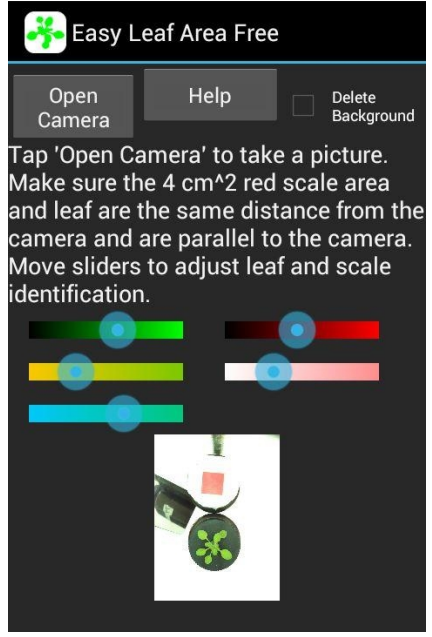

(a)

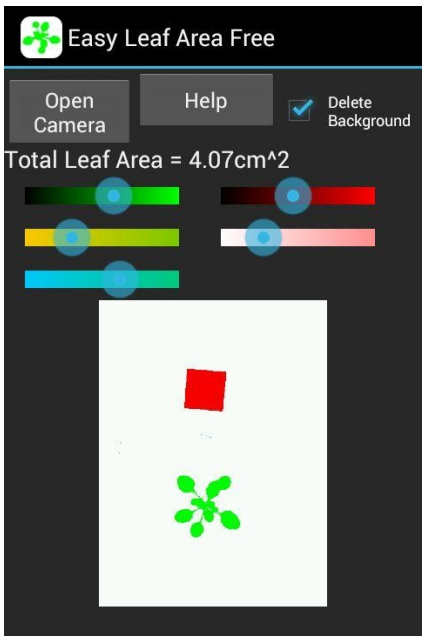

(b)

Figure 21. Easy Leaf Area: (a) Image capture and slider adjusting; (b) Image processing result.

Canopy Cover Free [51], developed by researchers from the Department of Plant Sciences from the University of California (California, United States), allows automatically and nondestructively measure and calculate the percentage of canopy coverage from the green area in images. Using sliders, adjustments can be made to identify the canopy area correctly. If the mobile device location is enabled, the latitude and longitude of the captured photo are automatically recorded. These coordinates and the percentage of coverage can be saved in a text file. According to the authors, some attention needs to be paid to camera height and angle, lens distortion, and the incidence angle of solar radiation, as problems with these factors may result in inaccurate canopy measurements. Figure 22 presents two screenshots of the application: the interface that allows adjusting the parameters to detect the area of the canopy correctly and the interface where the image processing result is displayed.

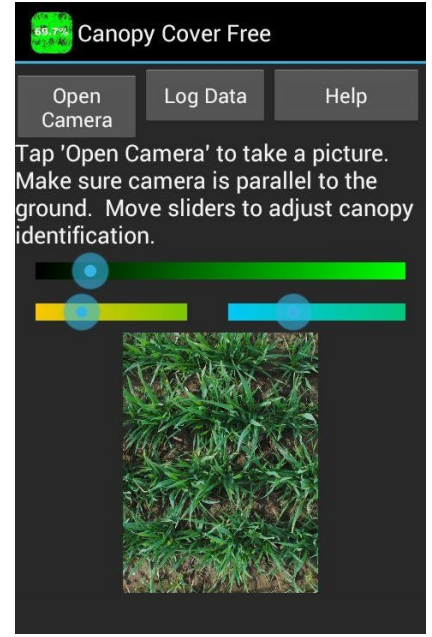

(a)

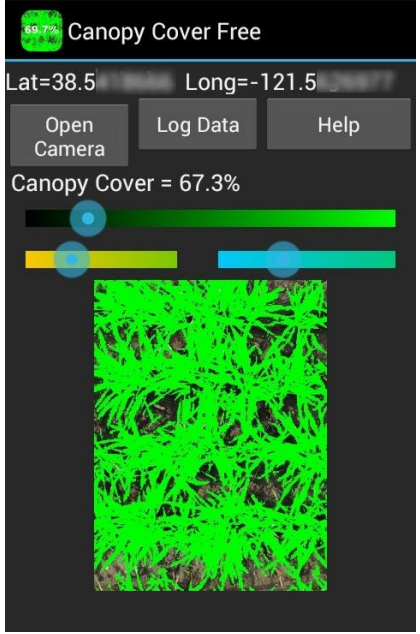

(b)

Figure 22. Canopy Cover Free: (a) Image capture and slider adjusting; (b) Image processing result.

Canopeo [52,53], developed by researchers at Oklahoma State University (Stillwater, OK, USA), is an application that allows monitoring crop growth through the green canopy size calculation. Its operation is based on colorimetry, providing faster and more accurate in situ results than visual exams using similar tools such as SamplePoint [54] or SigmaScan Pro [55]. This tool has several utilities, including monitoring crop growth and quantifying the effect of environmental factors such 
as hail, snow, and so forth. The application offers the possibility to register users, allows saving the analyzed images for future consultations and also allows associating them with a geolocation. One of the features that sets this application apart from the rest presented in this paper is that it allows video processing and not just static images. Figure 23 presents three screenshots of the application-the main menu, the interface that allows visualizing the captured image and the interface where the image processing result is presented.

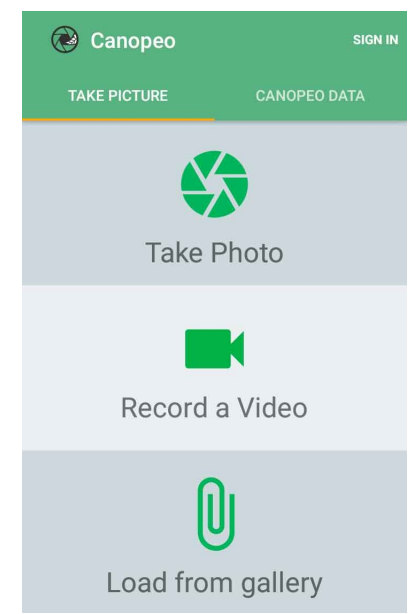

(a)

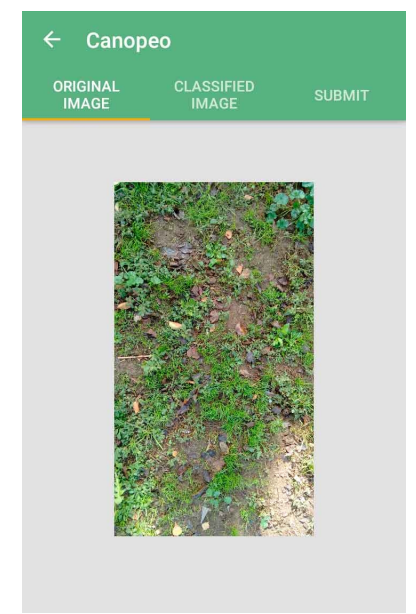

(b)

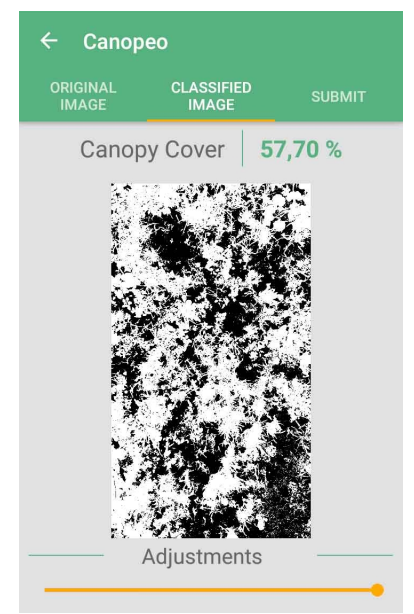

(c)

Figure 23. Canopeo: (a) Main menu; (b) Captured image visualization; (c) Image processing result.

PocketLAI [56-58], developed by researchers from the University of Milan (Milan, Italy) and Tuscia University (Viterbo, Italy), is a mobile application that allows estimating leaf area index using a smartphone. This application uses the smartphone camera and accelerometer to acquire images from below the canopy while the user is rotating the smartphone along its main axis. When the view angle reaches $57.5^{\circ}$, the frames are automatically processed to detect sky pixels via two dedicated segmentation strategies, one for clear sky and the other for a cloudy sky. The segmentation algorithm is responsible for determining the opening fraction of the canopy, that is, the part of the canopy that allows the light passing. Once processed, LAI values are stored in a table with information of date, time and GPS coordinates. The tables with LAI estimates and related metadata can be exported as CSV or SHP (allows to directly load data in a GIS application) files. Figure 24 presents two screenshots of the application-the image capture interface where the user must indicate if the sky is clear or cloudy and the interface where the LAI reading and its metadata can be visualized. It is also from this last interface that the user can import/export their data.

Sentinel-2 NDVI Maps [59], developed by Sinergise (Ljubljana, Slovenia), is a Geopedia World Sentinel version for mobile devices and allows viewing the current NDVI map based on Sentinel-2 satellite data provided by Copernicus. This NDVI map allows farmers to generally know the health of the plants in each region of their crops. The application provides five layers of images, namely, the Open Street Map layer for general navigation, two layers of vegetation index (NDVI and EVI-enhanced vegetation index) provided by Sentinel- 2 and two layers with the true and false colors also provided by Sentinel-2. These layers have a maximum zoom limit, allowing a maximum resolution of $15 \mathrm{~m} /$ pixel. The paid version of the application allows zooming four times higher than the free version. Only the latest image data with a maximum cloud coverage of $20 \%$ is displayed. Figure 25 presents three screenshots of the application: the Open Street Map layer view, the true color map layer view and the NDVI map layer view. 


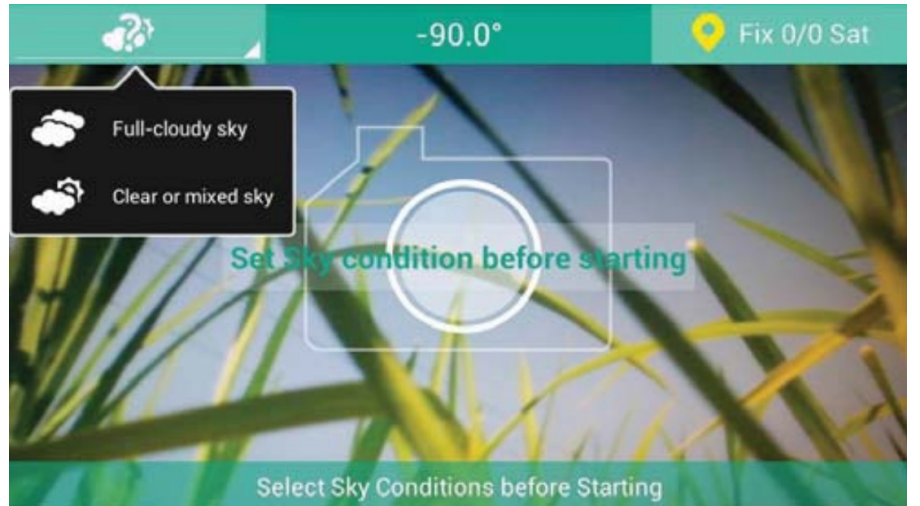

(a)

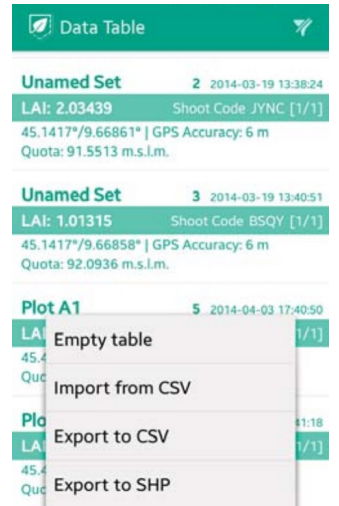

(b)

Figure 24. PocketLAI: (a) Measuring mode interface; (b) Data table with leaf area index (LAI) readings and related metadata, as well as import/export options.

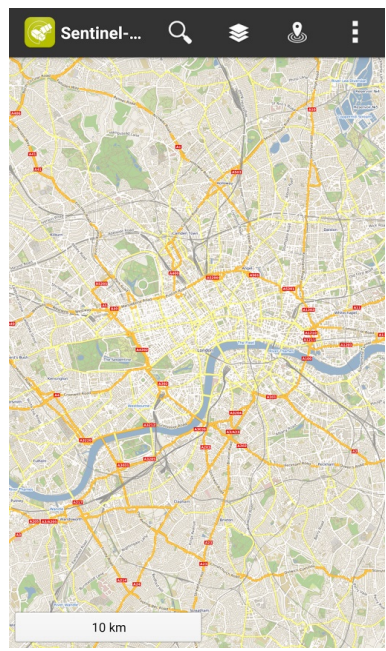

(a)

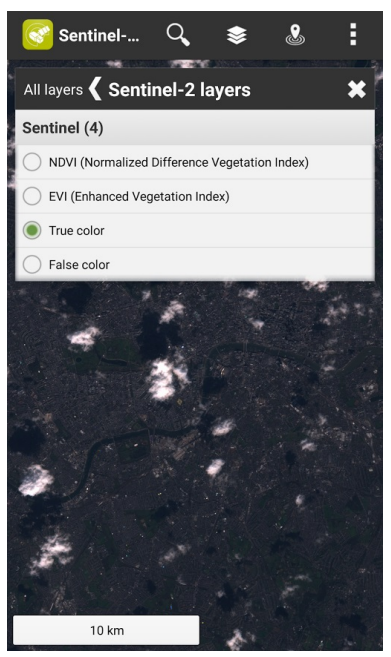

(b)

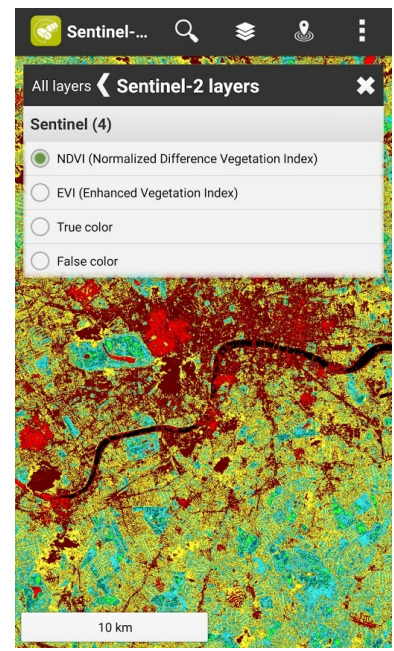

(c)

Figure 25. Sentinel-2 NDVI Maps: (a) Visualizing the Open Street Map layer; (b) Visualizing the true color map layer; (c) Visualizing the NDVI map layer.

OneSoil Scouting [60] is a mobile application developed by the startup OneSoil (Minsk, Belarus) specialized in crop monitoring using European satellite images with a resolution of 8-10 m per pixel. This application allows farmers to monitor their fields/crops continuously. For this, it is only necessary to select in the map the area where the crop is located and the application will automatically determine its limits through an AI algorithm. Then, the application calculates the NDVI using satellite images and presents a colorized photographic report showing the health of the plants. Images are updated every 3-5 days, and a notification system can be enabled to notify the user when a new image becomes available. This application allows farmers to detect anomalies in crop growth and create notes of these anomalies by associating them with a comment and a photo (if necessary). The application also allows visualizing weather forecasts, useful to support farmers decisions about the ideal time to spray or harvest crops. Figure 26 presents three screenshots of the application: the interface for adding and viewing fields, the interface for creating anomaly notes (represented by blue dots on the map) and the interface for displaying weather forecasts. 


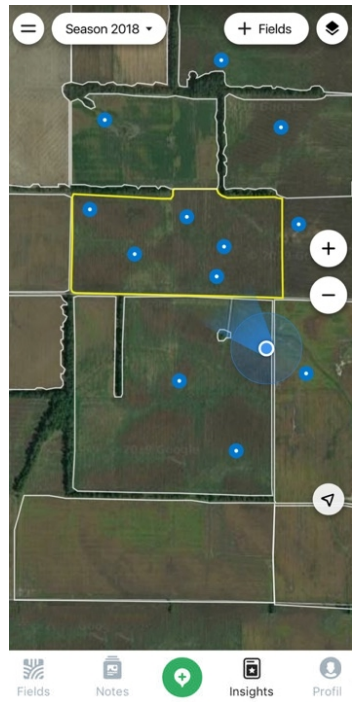

(a)

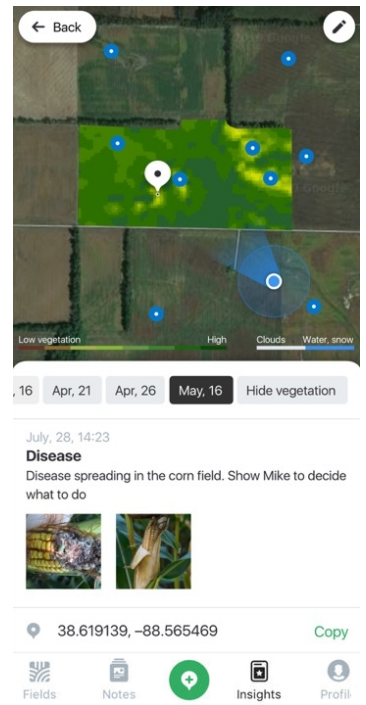

(b)

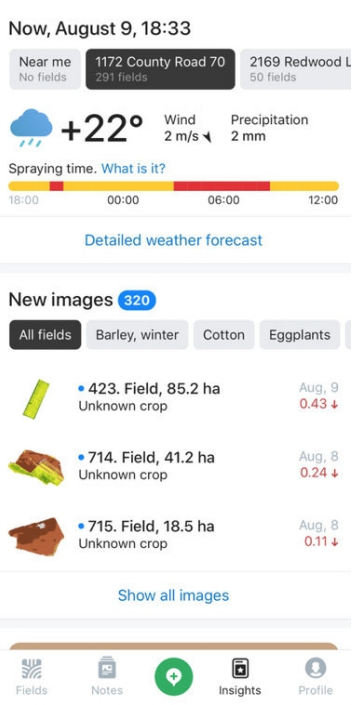

(c)

Figure 26. OneSoil Scouting: (a) Add and view the fields; (b) Create anomaly notes; (c) View weather forecasts.

Smart fLAIr (fast LAI retrieval) [61,62] is a mobile application developed by researchers at the University of Osnabrück (Osnabrück, Germany). It allows the in situ and nondestructive calculation of the leaf area index (LAI) based on gap fraction analysis, a widespread indirect and nondestructive methodology. For this, the application uses the smartphone's internal Ambient Light Sensor (ALS). To improve the gap fraction accuracy, the authors enhance the ALS by a diffuser cap combined with an optical band-pass filter. According to the authors, this application has good accuracy in measuring LAI, thus being a good low-cost alternative to other commercial solutions. Figure 27 presents three screenshots of the application: the main menu, the interface where the obtained LAI value is displayed and the interface where a table with various measurements and their metadata are presented.

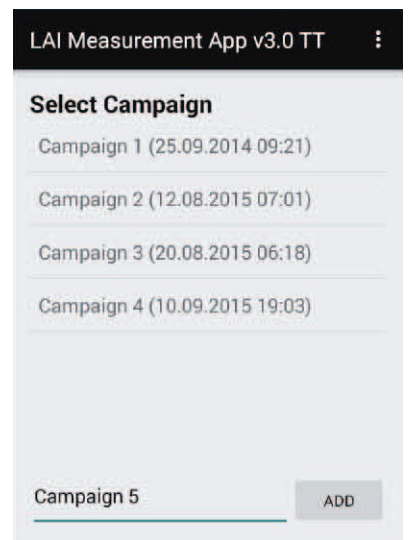

(a)

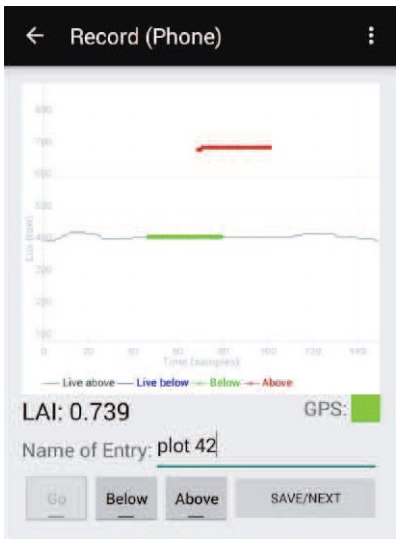

(b)

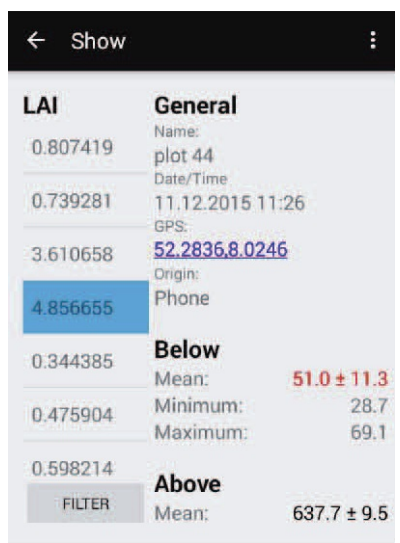

(c)

Figure 27. Smart fLAIr: (a) Main menu; (b) Measurement interface with LAI reading; (c) Measurement table with LAI readings and metadata.

\subsubsection{Crop Harvest}

vitisFlower [63] allows the automated and reliable evaluation (detection and counting) of the number of flowers of each bunch of grapes by analyzing an image of the inflorescence (part of the plant where the flowers are located). This tool uses the OpenCV library in order to maximize the computational efficiency of the smartphone. For the application to make a correct analysis is necessary 
to place a black surface behind the bunch to analyze. This application was developed by Televitis group from the University of La Rioja (La Rioja, Spain) in collaboration with four La Rioja SMEs as part of the Vinetics research project. It was one of the first applications developed for viticulture made available on the Google Play. Figure 28 presents three screenshots of the application: the main menu, the interface where the application's use instructions are presented and the interface where the processing result is presented.

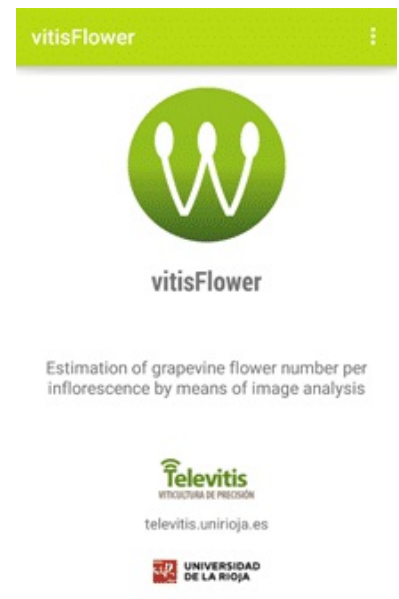

(a)

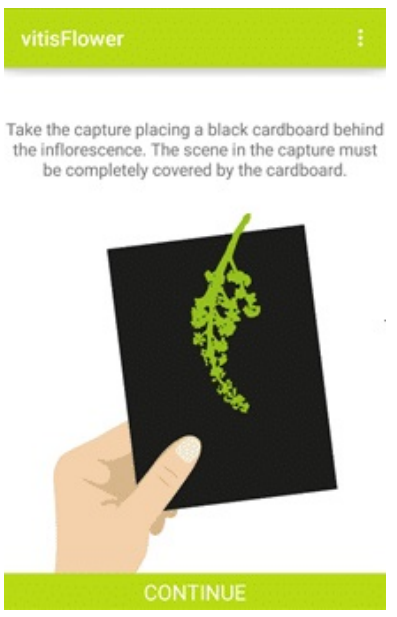

(b)

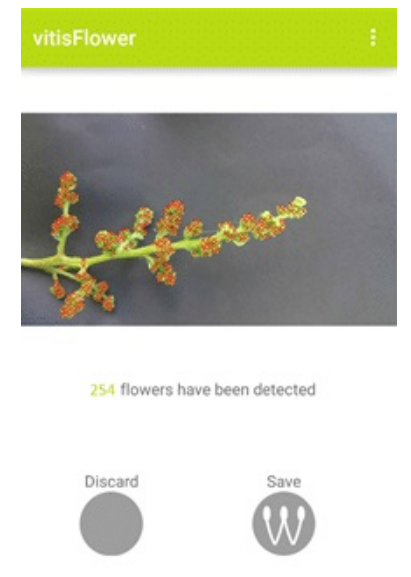

(c)

Figure 28. vitisFlower: (a) Main menu; (b) Use instructions; (c) Flower detection result.

vitisBerry [64], also developed by Televitis group from the University of La Rioja (La Rioja, Spain), is very similar to the vitisFower application, except that instead of allows the counting of the number of flowers, it allows the counting of the grapes when they are in their early stage of development. The identification of grape berries is made based on their circular shape, which allows their differentiation from other objects present in the image. It is, therefore, a practical and efficient tool that assists winegrowers in analyzing phenotypic information in their vineyards. Figure 29 presents three screenshots of the application: the main menu, the interface where the images are captured and the interface where the processing result is presented.

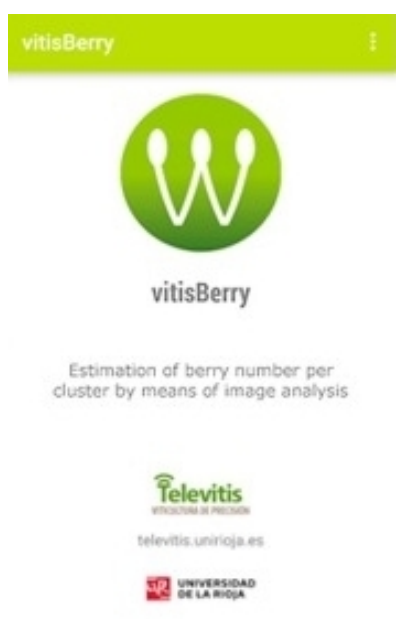

(a)

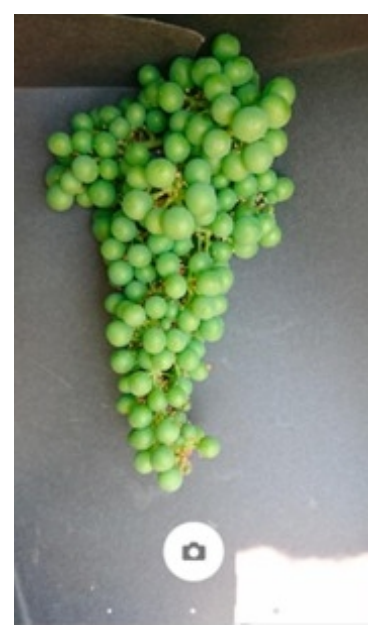

(b)

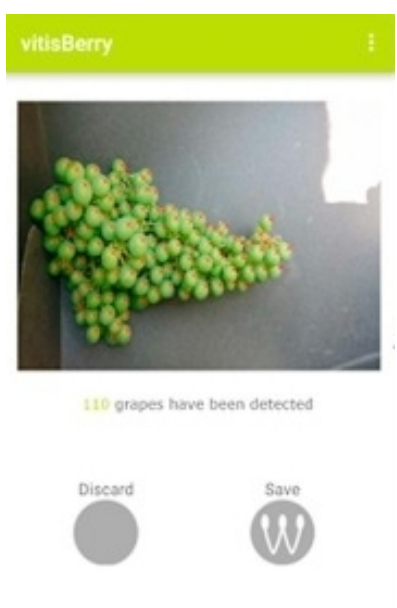

(c)

Figure 29. vitisBerry: (a) Main menu; (b) Capture image interface; (c) Grapevine berries detection result. 
FruitSize [65] was developed by a team of researchers from Central Queensland University (Queensland, Australia) to measure fruit size using images taken from a smartphone camera. For the application to correctly calculate the fruit size, it is necessary to place a blue background behind it with a yellow reference scale of known size. The user still needs to satisfy some operating restrictions, including the angle and distance between the camera and the background. The segmentation and processing of the fruit present in the images was performed using the OpenCV image processing library. To correctly calculate the size of the fruit, the application uses some camera parameters such as maximum resolution, focal length, and horizontal and vertical viewing angles. As an output, the application provides the size (width and length) of the processed fruit. The application also uses geolocation data, thus allowing to map the location of all processed fruits. According to the authors, it allows measuring, on average, 240 fruits per hour. Figure 30 presents an image showing the process of acquiring a photo of the fruit to be processed and a screenshot of the application showing the processed fruit size.

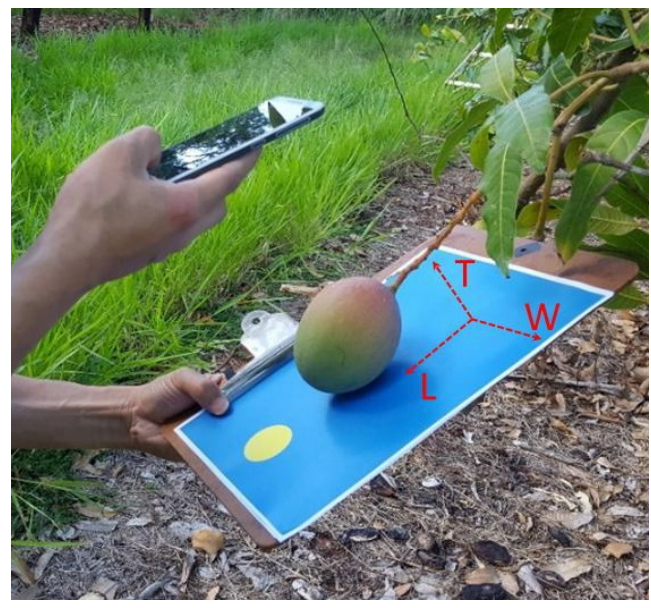

(a)

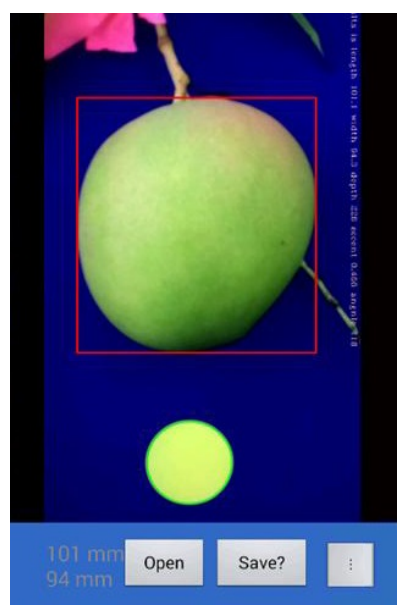

(b)

Figure 30. FruitSize: (a) Example of fruit photo capture; (b) Result of fruit size measurement.

\subsection{Farm Management}

This category includes applications that help farmers to achieve more efficient and effective management of farm resources and general agricultural activities: field mapping and soil information; machinery management and control of farm activities.

\subsubsection{Field Mapping and Soil Information}

Agri Precision [66], developed by Leonardo O. Moraes (Paraná, Brazil), allows, through GPS coordinates, to generate sample grids and to identify soil nutrients $(\mathrm{Mg}, \mathrm{Ca}, \mathrm{N}, \mathrm{P}, \mathrm{K}$, etc.) sample collection points. It also allows to calculate crop areas, create data tables and enter sampling results. Data can be exported to the computer or stored on the smartphone itself for further analysis. Figure 31 presents three screenshots of the application: the interface where the field is presented, the interface that shows the sample grid with the sample collection points and the table with the collected data.

GPS Fields Area Measure [67,68], developed by Farmis (Kaunas, Lithuania), allows measuring the perimeter and calculate the area of a field using satellite imagery. It becomes useful for farmers to account for the area that was cultivated with each of their crops. This requires the user to locate his/her field using GPS coordinates and mark its boundaries using points. Another measurement possibility consists of the user moving along the field boundaries and the application automatically marks these points. To get higher accuracy, the developers recommend using an external GPS receiver. These measurements can be made even on pivots (round-shaped fields). The application allows import 
and export measurements for later reference. Figure 32 presents three screenshots of the application: the interface where the field/crop boundaries are defined in order to calculate their area and perimeter, the interface where the history of taken measurements is shown and the interface where a specific measurement is presented.

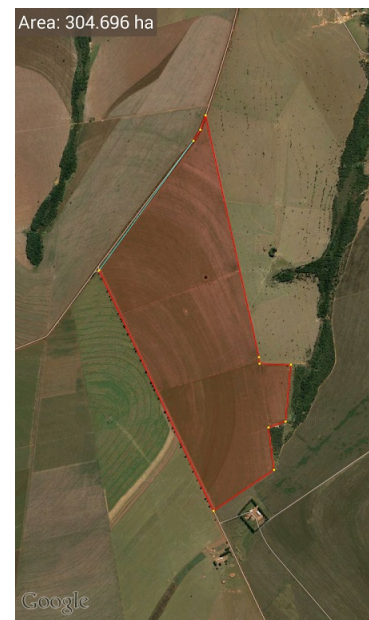

(a)

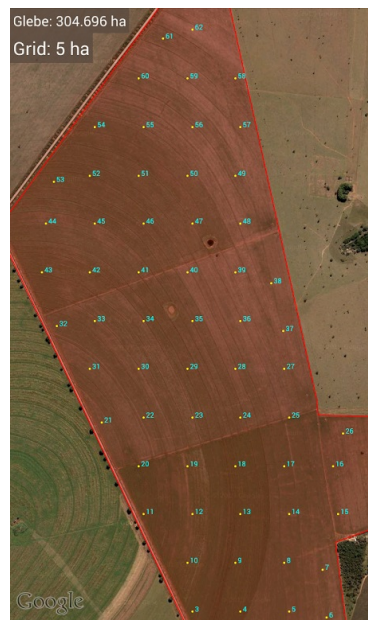

(b)

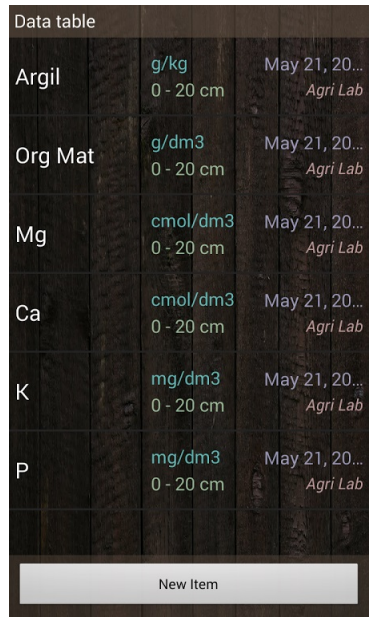

(c)

Figure 31. Agri Precision: (a) Visualizing filed area; (b) Visualizing sample grid; (c) Visualizing data table.

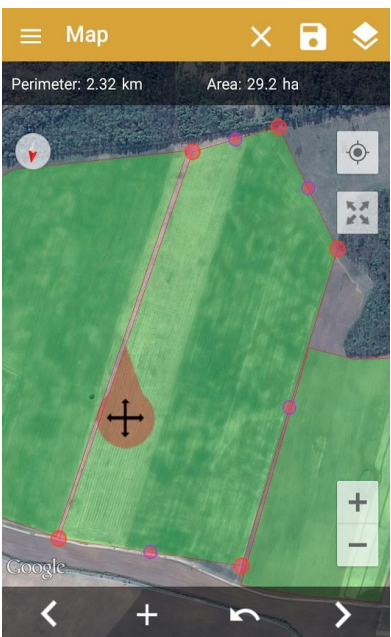

(a)

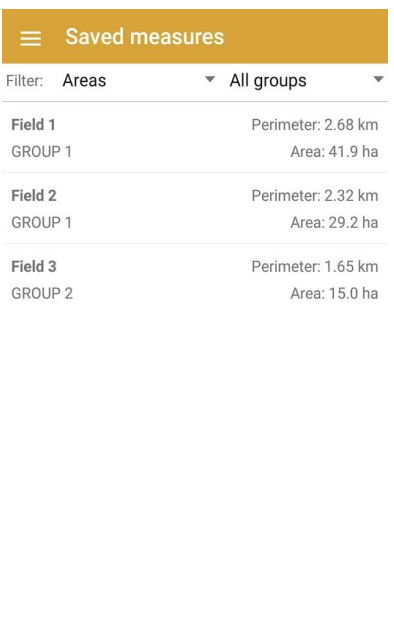

(b)

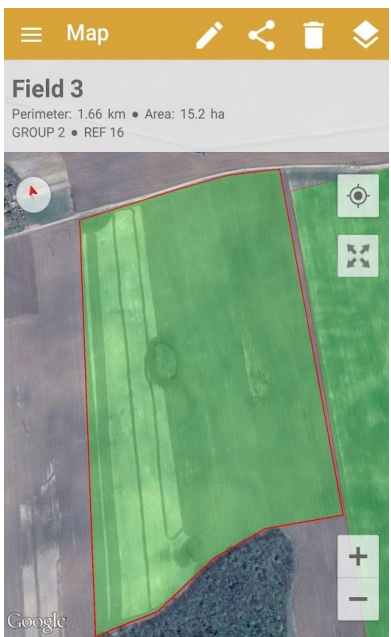

(c)

Figure 32. GPS Fields Area Measure: (a) Field boundary setting using GPS coordinates; (b) History of saved measures; (c) Field measurement visualization.

Soil Sampler [69], developed by Farmis (Kaunas, Lithuania), allows real-time crop samples georeferencing and gives to the user the best route to travel through the collection points. Its operation consists in drawing the crop map (which, as in the Fields Area Measure application, can be done by marking the boundary of the crop by points or moving along its boundaries) and setting the sample grid size for each culture (samples per $\mathrm{km}^{2}, \mathrm{~m}^{2}$, ha or $\mathrm{ft}^{2}$ ). The user must then move along the sampling points and, on each of them, mark the sample number on the sampling bag. Figure 33 presents three screenshots of the application: the interface that allows the user to define the number of samples to collect, the interface where the collection points distribution/location is displayed and the interface that allows viewing the history of saved fields. 


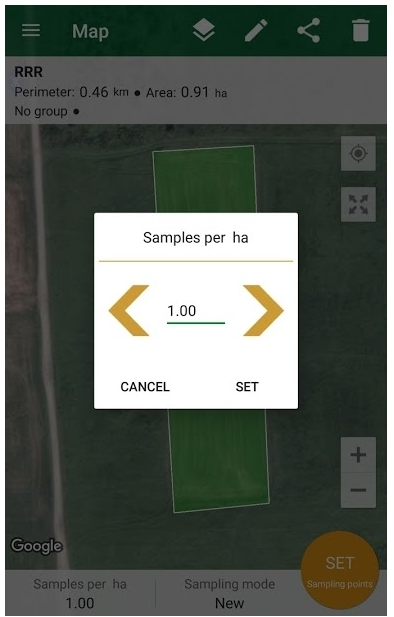

(a)

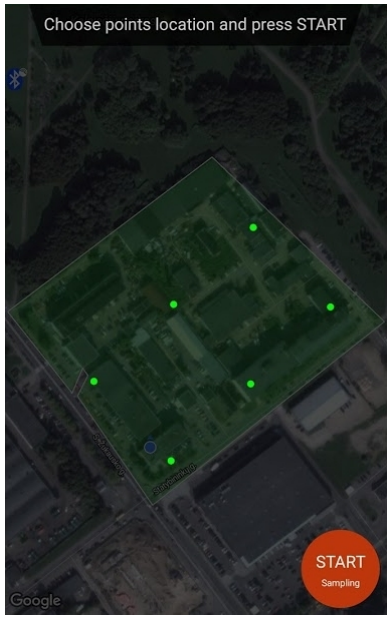

(b)

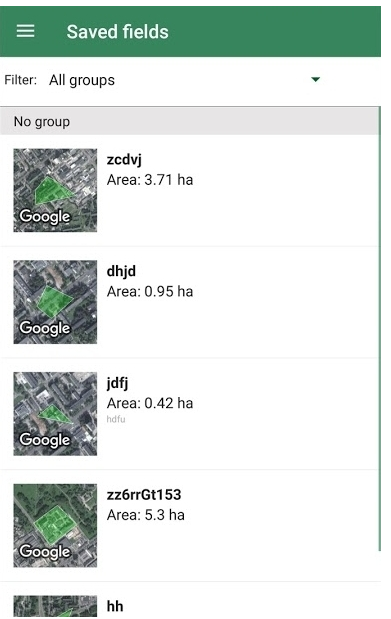

(c)

Figure 33. Soil Sampler: (a) Setting the desired number of samples; (b) Sample location visualization; (c) History of saved fields.

Nitrogen Index [70], developed at the United States Department of Agriculture (USDA) Agricultural Research Service (ARS) Soil Plant Nutrient Research Unit (New York, United States), is the first application developed for Android smartphones that allows calculating the nitrogen content in the soil. The purpose of this tool is to help farmers increase nutrient use efficiency by implementing best nitrogen management practices, thereby reducing their impact on the environment. This application is based on Nitrogen Index 4.4 [71] software and allows performing nitrogen leaching simulations, which are stored in the device's internal memory in NIN format (based on XML format). Simulations created and stored on the device can be sent via email or accessed through the device's file system by connecting it to a computer. Figure 34 presents two screenshots of the application: the main menu and the interface where some basic information is presented.

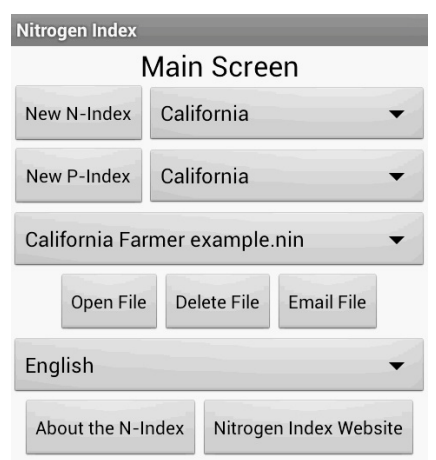

(a)

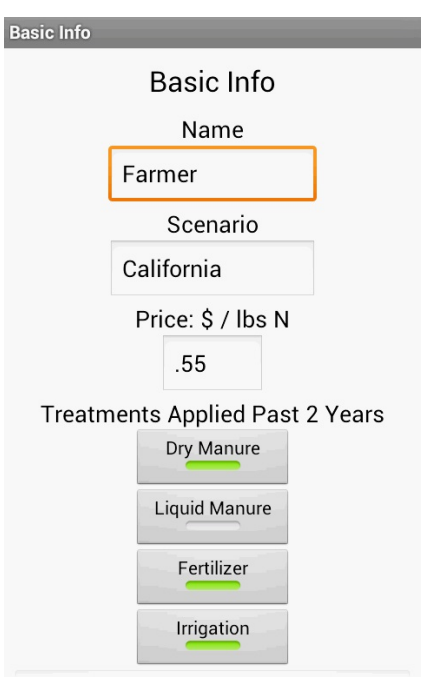

(b)

Figure 34. Nitrogen Index: (a) Main menu; (b) Basic info page.

\subsubsection{Machinery Management}

AgriBus-NAVI [72], developed by Agri Info Design (Hokkaido, Japan), simulates, on the smartphone, a GPS guidance system to assist in driving agricultural machines. With this application, farmers can drive machines in straight and evenly spaced lines since the actual position of the machine 
in relation to the baselines on which it must be driven is displayed. This application is based on "Agricultural Vehicle Navigation System" [73] software and "JP4572417B2" [74] patent, developed by the National Agricultural Research Organization (NARO). Figure 35 presents a screenshot of the application, where it is possible to visualize all controls/information that the application provides.

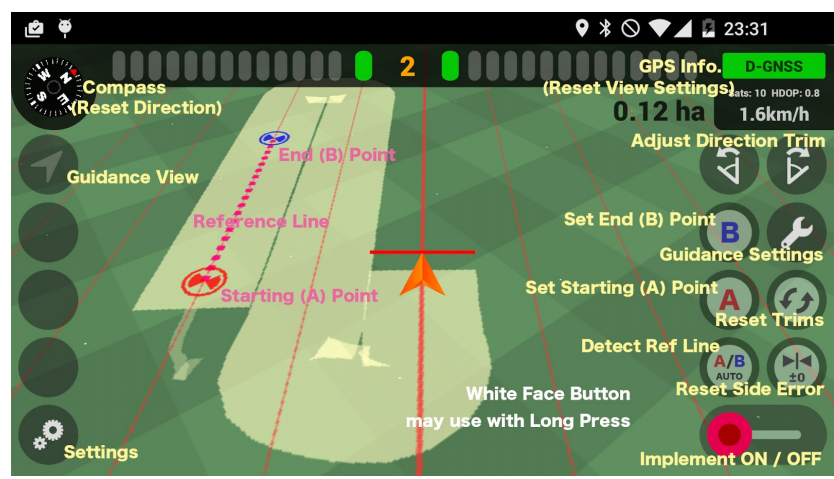

Figure 35. AgriBus-NAVI: Main interface.

Field Navigator [75], developed by Farmis (Kaunas, Lithuania), is similar to the AgriBus-NAVI application as it also allows simulating, on the smartphone, a GPS guidance system to assist in driving agricultural machines. With this application farmers can drive their machines along parallel lines, even in poor visibility and adverse weather conditions. Terrain limits, guidelines, obstacles and marking elements can be set and saved for future use. This application prevents farmers from passing more than once through an already treated or that he/she leaves untreated areas. For higher location accuracy, the application allows the connection, via Bluetooth, of various external GPS models. In future releases, the developers aim to provide some new features, such as activity logging, a 3D map-free driving assistant and a night mode for night work. Figure 36 presents three screenshots of the application: the navigation interface, the interface where the saved land history is displayed and the interface where an external GPS receiver can be configured for higher location accuracy.

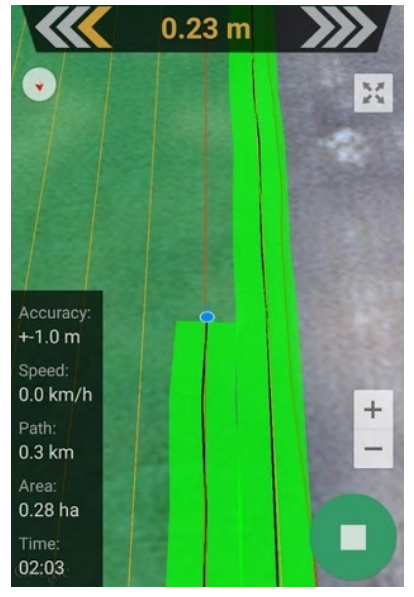

(a)

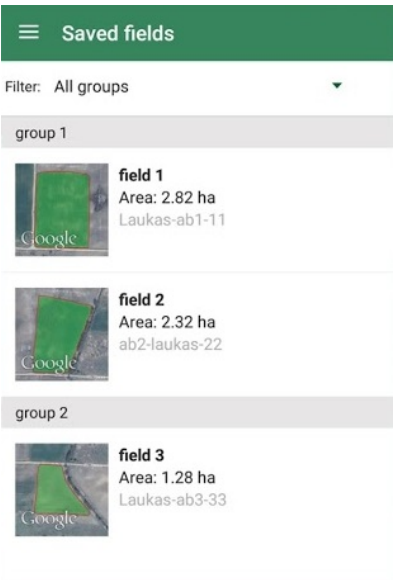

(b)

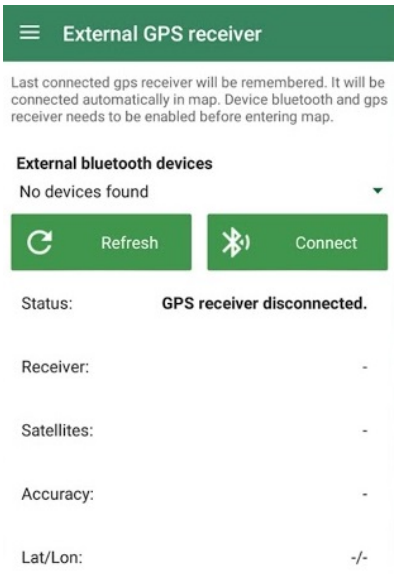

(c)

Figure 36. Field Navigator: (a) Navigation interface; (b) Land history for future use; (c) Connect external GPS receiver.

\subsubsection{Control of Farm Activities}

FarmManager [76] is a farm management application developed in the laboratories of the Technological Education Institute of Serres (Katerini, Greece). FarmManager's main features that make it useful for agricultural tasks are-its annual structure (all information produced and recorded during 
a year is stored in a file whose name is the year of work); crop personalization (there are no pre-defined process data, and farmers have to define their own processes and work data); easy field management (crop fields are defined directly on Google maps); land field data (significant data about the fields that should be accessible at any time, such as field size, geographical location, crop type, etc.); easy logging of operations (just being necessary to select the field name, the action that was performed, add any comment/information if necessary and click the "Save" button); and staff and equipment management (allows to record work and tasks performed by each employee, as well as register equipment and the services that them are allowed to perform). This application was developed for use in Greek agriculture and according to the authors, it can be used on crops from other regions around the world. Figure 37 presents three screenshots of the application: the main menu, the interface that allows to define and globally view the farmers' fields and the interface where fields data can be visualized.

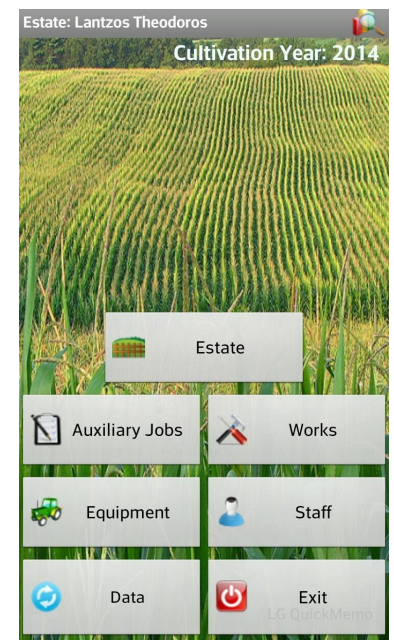

(a)

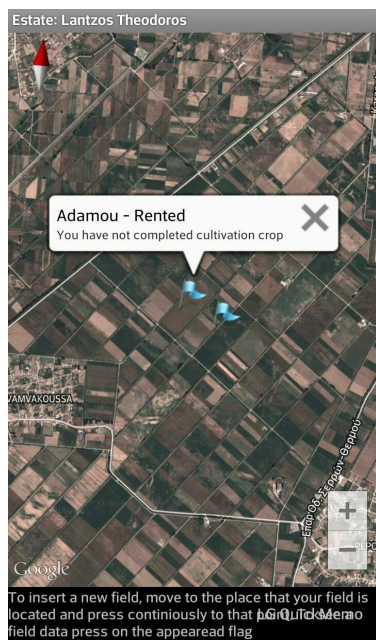

(b)

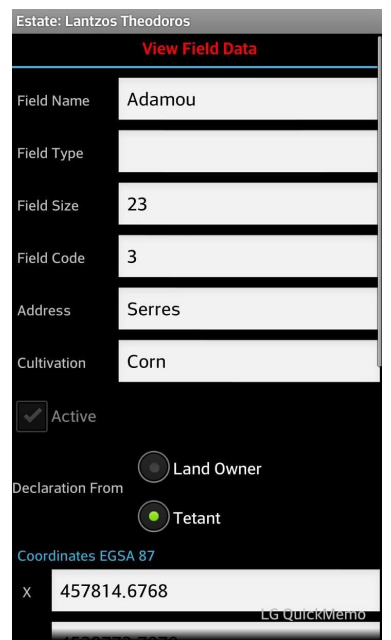

(c)

Figure 37. FarmManager: (a) Main menu; (b) Field definition and overview; (c) Field data visualization.

Agroop Cooperation-Crop Monitoring [77] is an agricultural management application developed by Agroop (Lisbon, Portugal) that allows farmers to manage their farms more intuitively and collaboratively. Among the various features presented by this application, can be highlighted the creation, management and monitorization of various lands/parcels/crops, the recommendation of field treatments, the analysis of data from the nearest weather station, and four features that are dependent on the use of the Stoock device (a device developed by the company that has five sensors: air temperature and humidity; soil temperature and humidity; and solar radiation). The processing of this data enable to identify the needs of crop water, to predict risk factors and to analyze and compare production factors. Figure 38 presents three screenshots of the application-the interface for creating and managing various fields and/or parcels, the interface for managing and monitoring crops and the interface for analyzing data from the Stoock device.

\subsection{Information System}

This category includes applications that provide essential information for farmers-agricultural tips and knowledge; market information; relevant agricultural news; chat with experts; and climate information.

AgriApp [78,79] is an application, developed by AgriApp (Bangalore, India), that provides complete information on several services related to agriculture, namely crop production and protection. The main features of the application are Package of Practices, Chat with Expert, Videos and News. The Package of Practices feature provides farmers with access to all common information and practices related to about 78 different crops. The Chat feature allows farmers to directly contact a panel discussion, 
which, according to the authors, consists of highly qualified agricultural specialists. With this feature, the user can submit photos, videos, or audio to help experts identify issues so they can provide relevant recommendations. In the Videos section, interesting agricultural information and some best practices are shown. The News feature allows farmers to view agriculture-related news and success stories that motivate less experienced farmers. Figure 39 presents three screenshots of the application: the main menu, the interface of agricultural practices divided by crop type and the interface that allows contact with a qualified specialist.

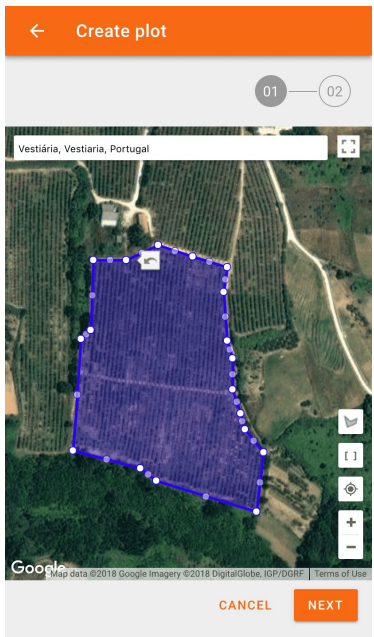

(a)

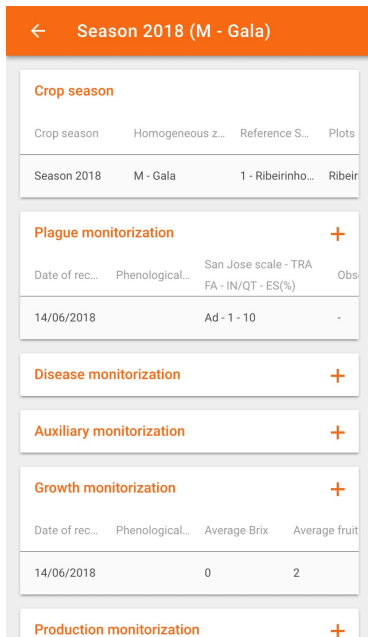

(b)

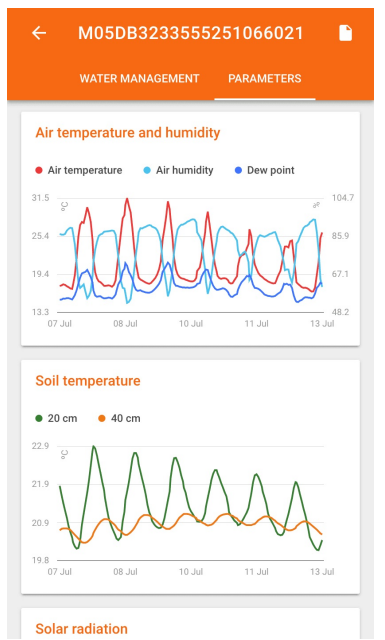

(c)

Figure 38. Agroop Cooperation: (a) Create and manage various land and/or parcels; (b) Manage and monitor crops; (c) Analysis of data from the Stoock device.

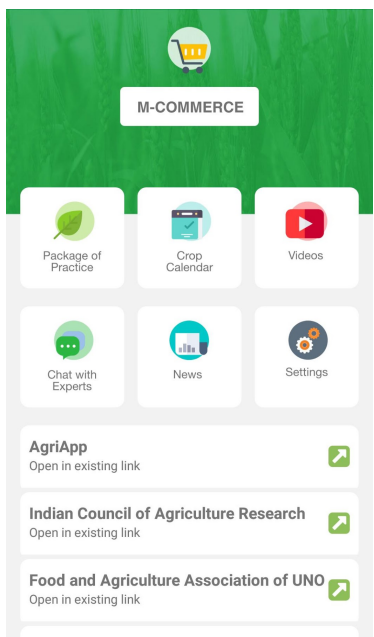

(a)

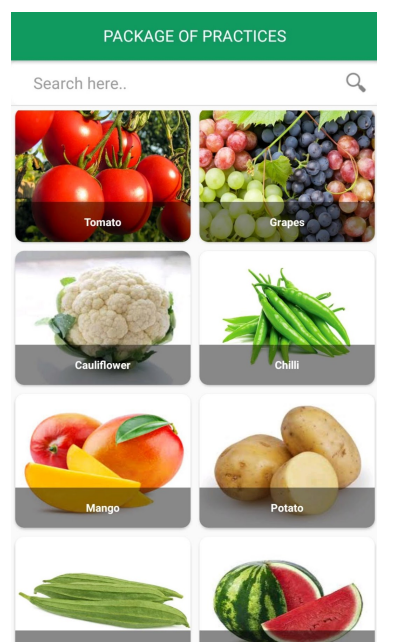

(b)

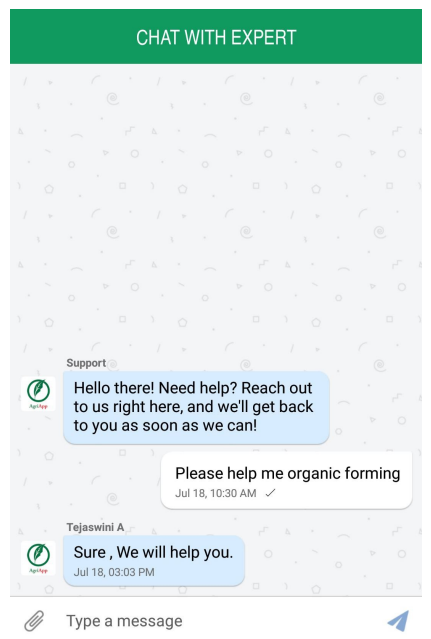

(c)

Figure 39. AgriApp: (a) Main menu; (b) Package of practices; (c) Chat with expert.

\section{Discussion}

In this section, a comparative table (Table 3) of all the applications covered in this work is presented and a discussion about each of the parameters used in the comparison is made. A total of 38 applications were presented and the parameters considered are as follows-type of application; processing type; operating platform and source from which the application was found; download availability; languages in which it is available; need for the Internet connection; use of internal sensors; need for external sensors; possibility to save and reuse data; interface and ease of use. Figure 40 
presents a treemap chart summarizing the results obtained in this comparison and then a discussion of each compared parameter is made.

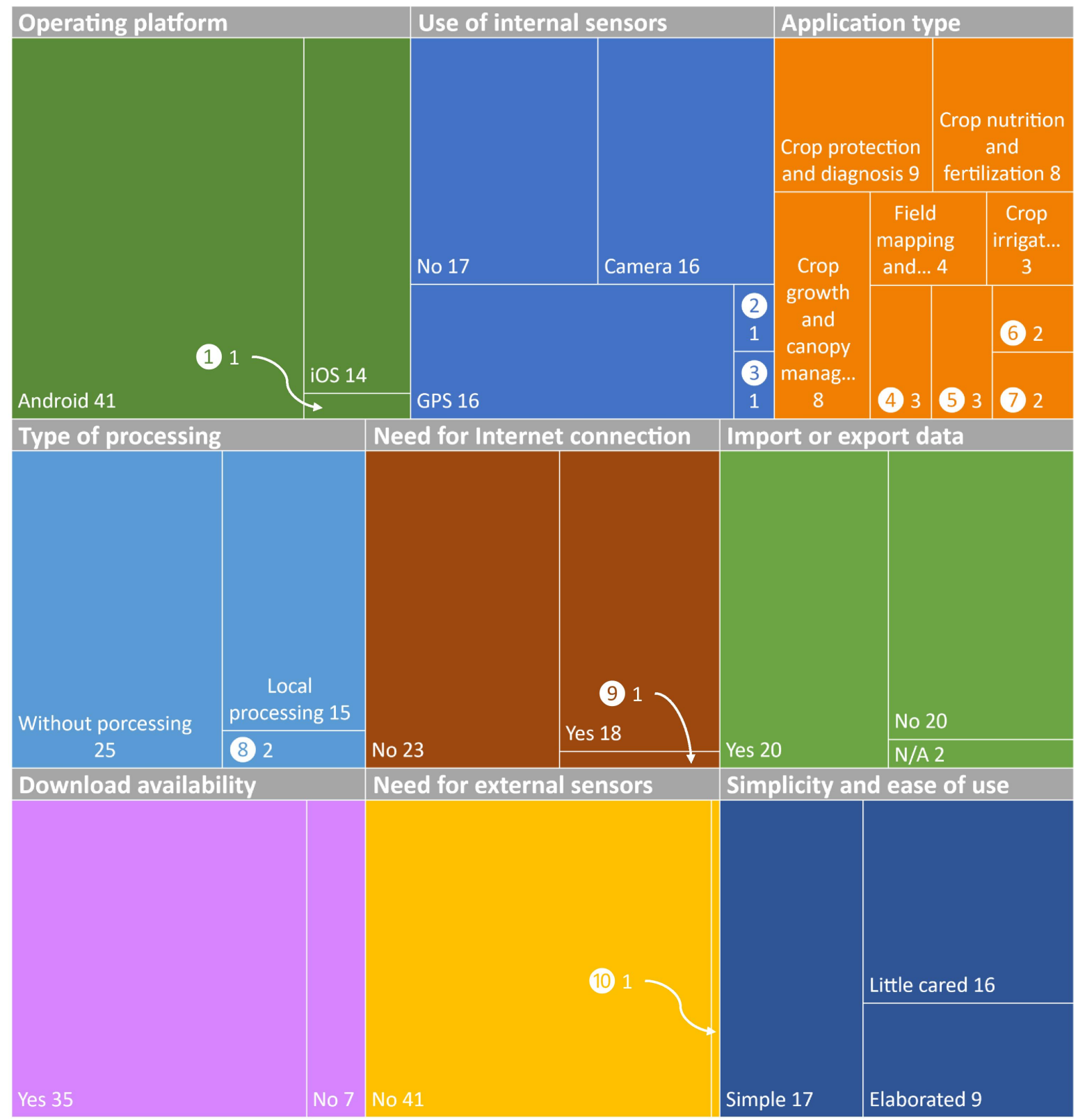

(1): Windows 10 Mobile; 2 : Accelerometer; 3 : Light sensor; (4): Crop harvest; 5 : Machinery management; 6: Control of farm activities; 7 : Information system; 8: Cloud processing; 9 : Yes/No; 10: Yes.

Figure 40. A treemap chart that summarizes the results obtained in this comparison. 
Table 3. Comparison of the applications presented in this paper.

\begin{tabular}{|c|c|c|c|c|c|c|c|c|c|c|c|}
\hline Work & Name & Type & $\begin{array}{c}\text { Processing } \\
\text { Type }\end{array}$ & $\begin{array}{l}\text { Platform } \\
\text { (Source) }\end{array}$ & $\begin{array}{c}\text { Available } \\
\text { for } \\
\text { Download }\end{array}$ & Languages & $\begin{array}{c}\text { Need } \\
\text { Internet }\end{array}$ & $\begin{array}{c}\text { Use } \\
\text { Internal } \\
\text { Sensors }\end{array}$ & $\begin{array}{c}\text { Need } \\
\text { External } \\
\text { Sensors }\end{array}$ & $\begin{array}{c}\text { Import or } \\
\text { Export } \\
\text { Data }\end{array}$ & $\begin{array}{c}\text { Interface } \\
\text { and Ease of } \\
\text { Use }\end{array}$ \\
\hline$[21,22]$ & Plantix & CPD & Cloud & $\begin{array}{c}\text { Android } \\
(\mathrm{GP})\end{array}$ & Yes & $\begin{array}{c}\mathrm{EN}, \mathrm{PT}, \mathrm{FR}, \\
\mathrm{ES}, * 1\end{array}$ & Yes & Camera & No & No & $\begin{array}{l}\text { Elaborated } \\
\text { Easy to use }\end{array}$ \\
\hline$[23,24]$ & BioLeaf & CPD & Local & $\begin{array}{c}\text { Android } \\
\text { (SDB) }\end{array}$ & Yes & $\begin{array}{c}\text { EN, PT, RU, } \\
\text { ES }\end{array}$ & No & Camera & No & Yes & $\begin{array}{c}\text { Simple } \\
\text { Easy to use }\end{array}$ \\
\hline [25] & E-agree & CPD & Cloud & $\begin{array}{c}\text { Android } \\
\text { (SDB) }\end{array}$ & No & EN, MR & Yes & Camera & No & No & $\begin{array}{l}\text { Little cared } \\
\text { Easy to use }\end{array}$ \\
\hline [26] & $\begin{array}{l}\text { ADAMA } \\
\text { Bullseye }\end{array}$ & CPD & No & $\begin{array}{l}\text { Android, iOS } \\
\text { (AS) }\end{array}$ & Yes & EN & No & No & No & No & $\begin{array}{l}\text { Elaborated } \\
\text { Easy to use }\end{array}$ \\
\hline$[27,28]$ & PMapp & CPD & No & $\begin{array}{c}\text { Android } \\
\text { (SDB) }\end{array}$ & Yes & EN & No & No & No & Yes & $\begin{array}{l}\text { Little cared } \\
\text { Easy to use }\end{array}$ \\
\hline$[29,30]$ & Plant Disease & CPD & Local & $\begin{array}{l}\text { Win10Mob } \\
\text { (SDB) }\end{array}$ & No & EN, EL & No & $\begin{array}{c}\text { Camera, } \\
\text { GNSS }\end{array}$ & No & No & $\begin{array}{l}\text { Elaborated } \\
\text { Easy to use }\end{array}$ \\
\hline [31] & ImScope & CPD & Local & $\begin{array}{l}\text { Android } \\
(\mathrm{GP})\end{array}$ & Yes & EN, ES & No & Camera & No & No & $\begin{array}{l}\text { Little cared } \\
\text { Easy to use }\end{array}$ \\
\hline [32] & Agrobase & CPD & No & $\begin{array}{l}\text { Android, iOS } \\
\text { (AS) }\end{array}$ & Yes & $\begin{array}{c}\text { EN, PT, FR, } \\
\text { ZH, AR, NL, } \\
\text { BG, FI, }{ }^{\#}\end{array}$ & No & No & No & No & $\begin{array}{l}\text { Simple } \\
\text { Easy to use }\end{array}$ \\
\hline [33] & DropLeaf & $\mathrm{CNF}$ & Local & $\begin{array}{l}\text { Android } \\
\text { (SDB) }\end{array}$ & Yes & $\begin{array}{c}\text { EN, PT, ES, } \\
\text { RU }\end{array}$ & No & Camera & No & No & $\begin{array}{l}\text { Simple } \\
\text { Easy to use }\end{array}$ \\
\hline$[34]$ & $\begin{array}{c}\text { Crop } \\
\text { Nutrient } \\
\text { Deficiencies }\end{array}$ & $\mathrm{CNF}$ & No & $\begin{array}{c}\text { Android, iOS } \\
\text { (GP) }\end{array}$ & Yes & EN & Yes & No & No & No & $\begin{array}{l}\text { Elaborated } \\
\text { Easy to use }\end{array}$ \\
\hline
\end{tabular}


Table 3. Cont.

\begin{tabular}{|c|c|c|c|c|c|c|c|c|c|c|c|}
\hline Work & Name & Type & $\begin{array}{c}\text { Processing } \\
\text { Type }\end{array}$ & $\begin{array}{l}\text { Platform } \\
\text { (Source) }\end{array}$ & $\begin{array}{c}\text { Available } \\
\text { for } \\
\text { Download }\end{array}$ & Languages & $\begin{array}{c}\text { Need } \\
\text { Internet }\end{array}$ & $\begin{array}{c}\text { Use } \\
\text { Internal } \\
\text { Sensors }\end{array}$ & $\begin{array}{c}\text { Need } \\
\text { External } \\
\text { Sensors }\end{array}$ & $\begin{array}{l}\text { Import or } \\
\text { Export Data }\end{array}$ & $\begin{array}{l}\text { Interface and } \\
\text { Ease of Use }\end{array}$ \\
\hline [35] & $\begin{array}{c}\text { Yara } \\
\text { TankmixIT }\end{array}$ & $\mathrm{CNF}$ & No & $\begin{array}{c}\text { Android, iOS } \\
\text { (GP) }\end{array}$ & Yes & $\begin{array}{c}\text { EN, PT, IT, DE, } \\
\text { DA, ES, FR, }{ }^{\prime}\end{array}$ & Yes & No & No & Yes & $\begin{array}{l}\text { Little cared } \\
\text { Easy to use }\end{array}$ \\
\hline [36] & SpraySelect & $\mathrm{CNF}$ & No & $\begin{array}{l}\text { Android, iOS } \\
\text { (GP) }\end{array}$ & Yes & EN & Yes & No & No & No & $\begin{array}{l}\text { Elaborated } \\
\text { Easy to use }\end{array}$ \\
\hline [37] & SnapCard & CNF & Local & $\begin{array}{l}\text { Android, iOS } \\
\text { (SDB) }\end{array}$ & Yes & EN & No & Camera & No & Yes & $\begin{array}{c}\text { Simple } \\
\text { Easy to use }\end{array}$ \\
\hline [38] & EcoFert & $\mathrm{CNF}$ & No & $\begin{array}{l}\text { Android } \\
\text { (SDB) }\end{array}$ & No & EN, ES, FR, DE & Yes & No & No & Yes & $\begin{array}{l}\text { Little cared } \\
\text { Easy to use }\end{array}$ \\
\hline [39] & $\begin{array}{c}\text { Smartirrigation } \\
\text { Cotton }\end{array}$ & CNF & No & $\begin{array}{l}\text { Android, iOS } \\
\text { (SDB) }\end{array}$ & Yes & EN & Yes & GNSS & No & Yes & $\begin{array}{l}\text { Elaborated } \\
\text { Easy to use }\end{array}$ \\
\hline [40-42] & $\begin{array}{c}\text { Grapevine } \\
\text { Water Stress }\end{array}$ & $\mathrm{CI}$ & Local & $\begin{array}{l}\text { Android } \\
\text { (SDB) }\end{array}$ & No & $\mathrm{EN}$ & No & No & $\begin{array}{l}\text { FLIR } \\
\text { One }\end{array}$ & - & $\begin{array}{c}\text { Simple } \\
\text { Easy to use }\end{array}$ \\
\hline [43] & pCAPS & $\mathrm{CI}$ & Local & $\begin{array}{l}\text { Android } \\
\text { (SDB) }\end{array}$ & No & EN & No & $\begin{array}{l}\text { Camera, } \\
\text { GNSS }\end{array}$ & No & Yes & $\begin{array}{l}\text { Little cared } \\
\text { Easy to use }\end{array}$ \\
\hline [45] & EVAPO & $\mathrm{CI}$ & No & $\begin{array}{l}\text { Android } \\
\text { (SDB) }\end{array}$ & Yes & EN & Yes & GNSS & No & Yes & $\begin{array}{c}\text { Simple } \\
\text { Easy to use }\end{array}$ \\
\hline [46-48] & VitiCanopy & CGCM & Local & $\begin{array}{l}\text { Android, iOS } \\
\text { (SDB) }\end{array}$ & Yes & EN & No & $\begin{array}{l}\text { Camera, } \\
\text { GNSS }\end{array}$ & No & Yes & $\begin{array}{c}\text { Simple } \\
\text { Easy to use }\end{array}$ \\
\hline [49] & Easy Leaf Area & CGCM & Local & $\begin{array}{l}\text { Android } \\
\text { (SDB) }\end{array}$ & Yes & EN & No & Camera & No & No & $\begin{array}{l}\text { Little cared } \\
\text { Easy to use }\end{array}$ \\
\hline [51] & $\begin{array}{c}\text { Canopy Cover } \\
\text { Free }\end{array}$ & CGCM & Local & $\begin{array}{c}\text { Android } \\
\text { (GP) }\end{array}$ & Yes & EN & No & $\begin{array}{l}\text { Camera, } \\
\text { GNSS }\end{array}$ & No & Yes & $\begin{array}{l}\text { Little cared } \\
\text { Easy to use }\end{array}$ \\
\hline
\end{tabular}


Table 3. Cont.

\begin{tabular}{|c|c|c|c|c|c|c|c|c|c|c|c|}
\hline Work & Name & Type & $\begin{array}{c}\text { Processing } \\
\text { Type }\end{array}$ & $\begin{array}{c}\text { Platform } \\
\text { (Source) }\end{array}$ & $\begin{array}{c}\text { Available } \\
\text { for } \\
\text { Download }\end{array}$ & Languages & $\begin{array}{c}\text { Need } \\
\text { Internet }\end{array}$ & $\begin{array}{c}\text { Use } \\
\text { Internal } \\
\text { Sensors }\end{array}$ & $\begin{array}{c}\text { Need } \\
\text { External } \\
\text { Sensors }\end{array}$ & $\begin{array}{c}\text { Import or } \\
\text { Export Data }\end{array}$ & $\begin{array}{c}\text { Interface and } \\
\text { Ease of Use }\end{array}$ \\
\hline$[52,53]$ & Canopeo & CGCM & Local & $\begin{array}{l}\text { Android, iOS } \\
\text { (SDB) }\end{array}$ & Yes & $\mathrm{EN}$ & No & $\begin{array}{c}\text { Camera, } \\
\text { GNSS }\end{array}$ & No & Yes & $\begin{array}{c}\text { Simple } \\
\text { Easy to use }\end{array}$ \\
\hline [56-58] & PocketLAI & CGCM & Local & $\begin{array}{l}\text { Android } \\
\text { (SDB) }\end{array}$ & No & $\mathrm{EN}$ & No & $\begin{array}{c}\text { Camera, GNSS, } \\
\text { Accelerometer }\end{array}$ & No & Yes & $\begin{array}{c}\text { Simple } \\
\text { Easy to use }\end{array}$ \\
\hline [59] & $\begin{array}{c}\text { Sentinel-2 } \\
\text { NDVI Maps }\end{array}$ & CGCM & No & $\begin{array}{l}\text { Android } \\
\text { (GP) }\end{array}$ & Yes & $\mathrm{EN}$ & Yes & No & No & No & $\begin{array}{c}\text { Simple } \\
\text { Easy to use }\end{array}$ \\
\hline$[60]$ & $\begin{array}{l}\text { OneSoil } \\
\text { Scouting }\end{array}$ & CGCM & No & $\begin{array}{l}\text { Android, iOS } \\
\text { (AS) }\end{array}$ & Yes & $\begin{array}{c}\text { EN, PT, FR, ES, } \\
\text { IT, DE, RU }\end{array}$ & Yes & No & No & No & $\begin{array}{l}\text { Elaborated } \\
\text { Easy to use }\end{array}$ \\
\hline$[61,62]$ & Smart fLAIr & CGCM & No & $\begin{array}{l}\text { Android } \\
\text { (SDB) }\end{array}$ & Yes & $\mathrm{EN}$ & No & $\begin{array}{c}\text { Ambient } \\
\text { Light, GNSS }\end{array}$ & No & Yes & $\begin{array}{l}\text { Little cared } \\
\text { Easy to use }\end{array}$ \\
\hline [63] & vitisFlower & $\mathrm{CH}$ & Local & $\begin{array}{l}\text { Android } \\
\text { (SDB) }\end{array}$ & Yes & EN, ES & No & Camera & No & Yes & $\begin{array}{c}\text { Simple } \\
\text { Easy to use }\end{array}$ \\
\hline [64] & vitisBerry & $\mathrm{CH}$ & Local & $\begin{array}{l}\text { Android } \\
\text { (SDB) }\end{array}$ & No & EN, ES & No & Camera & No & Yes & $\begin{array}{c}\text { Simple } \\
\text { Easy to use }\end{array}$ \\
\hline [65] & FruitSize & $\mathrm{CH}$ & Local & $\begin{array}{l}\text { Android } \\
\text { (SDB) }\end{array}$ & Yes & $\mathrm{EN}$ & No & $\begin{array}{c}\text { Camera, } \\
\text { GNSS }\end{array}$ & No & Yes & $\begin{array}{l}\text { Little cared } \\
\text { Easy to use }\end{array}$ \\
\hline [66] & Agri Precision & FMSI & No & $\begin{array}{l}\text { Android } \\
\text { (GP) }\end{array}$ & Yes & $\begin{array}{c}\text { EN, PT, IT, ES, } \\
\text { FR }\end{array}$ & No & GNSS & No & Yes & $\begin{array}{l}\text { Little cared } \\
\text { Easy to use }\end{array}$ \\
\hline$[67,68]$ & $\begin{array}{l}\text { GPS Fields } \\
\text { Area Measure }\end{array}$ & FMSI & No & $\begin{array}{l}\text { Android, iOS } \\
\text { (AS) }\end{array}$ & Yes & $\begin{array}{c}\text { EN, PT, FR, ES, } \\
\text { ZH, AR, CS, } \\
\text { NL, }{ }^{\prime}\end{array}$ & No & GNSS & No & Yes & $\begin{array}{c}\text { Simple } \\
\text { Easy to use }\end{array}$ \\
\hline
\end{tabular}


Table 3. Cont.

\begin{tabular}{|c|c|c|c|c|c|c|c|c|c|c|c|}
\hline Work & Name & Type & $\begin{array}{c}\text { Processing } \\
\text { Type }\end{array}$ & $\begin{array}{l}\text { Platform } \\
\text { (Source) }\end{array}$ & $\begin{array}{c}\text { Available } \\
\text { for } \\
\text { Download }\end{array}$ & Languages & $\begin{array}{c}\text { Need } \\
\text { Internet }\end{array}$ & $\begin{array}{c}\text { Use } \\
\text { Internal } \\
\text { Sensors }\end{array}$ & $\begin{array}{c}\text { Need } \\
\text { External } \\
\text { Sensors }\end{array}$ & $\begin{array}{l}\text { Import or } \\
\text { Export Data }\end{array}$ & $\begin{array}{l}\text { Interface and } \\
\text { Ease of Use }\end{array}$ \\
\hline [69] & Soil Sampler & FMSI & No & $\begin{array}{l}\text { Android } \\
\text { (GP) }\end{array}$ & Yes & $\begin{array}{l}\text { EN, PT, FR, } \\
\mathrm{ZH}, \mathrm{AR},{ }^{* 2}\end{array}$ & Yes & GNSS & No & Yes & $\begin{array}{c}\text { Simple } \\
\text { Easy to use }\end{array}$ \\
\hline$[70]$ & $\begin{array}{l}\text { Nitrogen } \\
\text { Index }\end{array}$ & FMSI & No & $\begin{array}{l}\text { Android } \\
\text { (SDB) }\end{array}$ & Yes & EN, ES & No & No & No & Yes & $\begin{array}{l}\text { Little cared } \\
\text { Easy to use }\end{array}$ \\
\hline [72] & AgriBus-NAVI & $\mathrm{MM}$ & No & $\begin{array}{c}\text { Android } \\
\text { (GP) }\end{array}$ & Yes & EN, PT, ES, \# & Yes & GNSS & No & No & $\begin{array}{l}\text { Simple } \\
\text { Easy to use }\end{array}$ \\
\hline [75] & $\begin{array}{c}\text { Field } \\
\text { Navigator }\end{array}$ & $\mathrm{MM}$ & No & $\begin{array}{l}\text { Android } \\
\text { (GP) }\end{array}$ & Yes & $\begin{array}{c}\text { EN, PT, FR, } \\
\mathrm{ZH},{ }^{* 3}\end{array}$ & Yes & GNSS & No & No & $\begin{array}{c}\text { Simple } \\
\text { Easy to use }\end{array}$ \\
\hline [76] & FarmManager & CFA & No & $\begin{array}{l}\text { Android } \\
\text { (SDB) }\end{array}$ & No & EN, EL & Yes & No & No & - & $\begin{array}{l}\text { Little cared } \\
\text { Easy to use }\end{array}$ \\
\hline [77] & $\begin{array}{c}\text { Agroop } \\
\text { Cooperation }\end{array}$ & CFA & No & $\begin{array}{l}\text { Android, iOS } \\
\text { (AS) }\end{array}$ & Yes & EN, PT & Yes & No & $\begin{array}{l}\text { Stoock } \\
\text { device }\end{array}$ & No & $\begin{array}{l}\text { Elaborated } \\
\text { Easy to use }\end{array}$ \\
\hline$[78,79]$ & AgriApp & IS & No & $\begin{array}{l}\text { Android } \\
\text { (GP) }\end{array}$ & Yes & EN & Yes & No & No & No & $\begin{array}{l}\text { Elaborated } \\
\text { Easy to use }\end{array}$ \\
\hline
\end{tabular}

Legend: CPD: crop protection and diagnosis; CNF: crop nutrition and fertilization; CI: crop irrigation; CGCM: crop growth and canopy management; CH: crop harvest; FMSI: field mapping and soil information; MM: machinery management; CFA: control of farm activities; IS: information system; Win10Mob: Windows 10 Mobile; SDB: scientific database; GP: Google Play; AS: App Store; AR: Arabic; BG: Bulgarian; BN: Bengali; CS: Czech; DA: Danish; DE: German; EL: Greek; EN: English; ES: Spanish; FI: Finnish; FR: French; GU: Gujarati; HI: Hindi; HU: Hungarian; ID: Indonesian; IT: Italian; KN: Kannada; LT: Lithuanian; LV: Latvian; ML: Malayalam; MR: Marathi; NL: Dutch; OR: Oriya; PA: Punjabi; PL: Polish; PT: Portuguese; RO: Romanian; RU: Russian; SK: Slovak; SL: Slovenian; SQ: Albanian; SR: Serbian; TA: Tamil; TE: Telugu; TR: Turkish; UK: Ukrainian; UR: Urdu; VI: Vietnamese; ZH: Chinese (Mandarin); Notes: ${ }^{* 1}$ : AR, BN, GU, HI, ID, KN, ML, MR, OR, PA, TA, TE, UR and VI; *2: BG, DE, EL, FI, HU, LT, PL, RO, RU, SR and TR; *3: AR, BG, DE, EL, ES, FI, HI, HU, ID, IT, LT, LV, NL, PL, RO, RU, SK, SL, SQ, SR, TR and UK; : : Application that may be available in more languages than indicated as the language is changed according to the language of the mobile device's operating system. 
The presented applications are distributed in the various categories and subcategories as follows: $8(21.1 \%)$ to crop protection and diagnosis; 7 (18.4\%) to crop nutrition and fertilization; 3 (8.0\%) to crop irrigation; $8(21.1 \%)$ to crop growth and canopy management; $3(8.0 \%)$ to crop harvest; $4(10.5 \%)$ to field mapping and soil information; $2(5.3 \%)$ to machinery management; $2(5.3 \%)$ to control of farm activities; and $1(2.6 \%)$ to information system.

Regarding the processing type, 21 (55.3\%) applications do not perform any data processing, 15 (39.5\%) applications perform local processing, that is, on the smartphone's processor, and $2(5.3 \%)$ applications perform processing on a remote server (cloud). Of the 17 applications that perform some type of processing, 16 [23-25,29-31,33,37,40-43,46-49,51-53,56-58,63-65] use image recognition and processing techniques, such as color space transformation, background subtraction, segmentation, binarization, noise reduction, shape recognition, and thresholding. Other applications [21,22], besides using imaging recognition techniques, also use AI-powered algorithms that run on a remote server (cloud) to help farmers identify pathogens on their crops. Usually, the applications that perform remote processing are more advanced and powered by DL, ML or AI algorithms.

Concerning the platforms for which the applications are available, 37 (97.4\%) run on Android from Google, $11(29.0 \%)$ run on iOS from Apple, and only $1(2.6 \%)$ is available for Windows Phone/Windows 10 Mobile from Microsoft. These values were expected, since Android currently has practically all the best-known applications. Moreover, new applications are usually first released on Android. Probably this is due to the application's approval process that is more straightforward in the Google Play. It was also expected that the percentage of applications available for Windows Phone/Windows 10 Mobile would be the lowest, as it is a system that has never been widely adopted by the technological community and always had limitations on its applications store. Although support for Windows Phone/Windows 10 Mobile ended in December 2019, we consider it relevant to include the Plant Disease application as it can serve as a basis for the development of similar applications for the mobile operating systems currently in use (Android and/or iOS).

About the availability for download, $30(79.0 \%)$ applications are available through the Google Play or the App Store platforms or the developers' pages, and $8(21.0 \%)$ applications are not available for download. All applications that are not available were developed at the research level, however, some authors intend to make them available for download in the future.

Concerning the languages in which the applications are available, $19(50.0 \%)$ applications are only available in English and 19 (50.0\%) are available in one or more languages in addition to English. Of these, Portuguese, Spanish, Chinese (Mandarin), Arabic and French stand out, being some of the most widely spoken languages in the world. Of the applications that were possible to test (available for download), it was found that most of them allow the user to define the language manually and only 4 applications (AgriBus-NAVI, GPS FieldsArea Measure, Yara TankmixIT and Agrobase) automatically adapt the language according to the language of the mobile device.

Regarding the need for Internet access, 16 (42.1\%) applications require this connection, and 22 (57.9\%) applications do not need it. This parameter depends a lot on the application type. An application that accesses data made available online, such as maps or forecasts, necessarily requires this connection. An application that only allows saving data locally (on the smartphone itself), for example, location of samples taken in the field, and do not send it to any remote server, does not need this connection. The current trend is to provide users with cloud storage (remote servers), which provides the advantage of allowing access to information through many different smartphones or, if the smartphone is damaged or lost, data is always safeguarded.

Concerning the use of internal sensors of the mobile device where applications run, 16 (42.1\%) use the camera, $15(39.5 \%)$ use the GNSS, $1(2.6 \%)$ uses the accelerometer, and $1(2.6 \%)$ uses the ambient light sensor. $14(36.8 \%)$ applications do not use any internal sensor of the mobile device. It is clear that the most used sensors are the image sensors (camera) and the GNSS sensors (GPS) followed by the accelerometer (motion sensor) and ambient light (environmental sensor). However, none of the applications use the other sensors presented in Section 1.3, such as the gyroscope, magnetometer, 
temperature, relative humidity, and pressure. The camera is used to collect images or videos that can be processed locally or sent to a remote server for further processing/analysis. In the applications presented in this paper, the collection of images is intended for the visual inspection of crops, namely for the detection of diseases $[21,22,25,29,30]$, plants damage detection $[23,24]$, obtaining health indicators [31], inspection of the coverage area of pesticide spraying [33,37], characterization of canopy area and architecture [43,46-49,51-53,56-58], and for crop yield estimation [63-65]. The GPS is used by applications in order to identify the location where some type of task is/was performed. These tasks can be the identification of a specific disease $[29,30]$, watering [39,45], measuring parameters related to the canopy [43,46-48,51-53,56-58,61,62], crop yield estimation [65], and soil sampling [66-69]. The GPS can also be used to assist in the agricultural machines navigation [72,75].

About the need for external sensors, only two (5.3\%) applications need it, and the remaining $36(94.7 \%)$ do not need any external sensor. This low use of external sensors is maybe related to the fact that we are increasingly looking to develop the most practical and portable solutions possible. A system where only the smartphone is needed is a more practical solution and often the ideal solution. Another reason for this low use of external sensors is that the most common sensors (accelerometer, gyroscope, GPS, temperature, relative humidity, camera, etc.) already equip almost all current smartphones. One of the applications that requires an external sensor is the Grapevine Water Stress [40-42]. This application requires the use of a thermal camera (FLIR One), however, it may no longer be necessary since there are already smartphones with an integrated thermal camera. The other application that needs an external sensor is the Agroop Cooperation [77]. Although this application works without the Stoock device (a device developed by the company that has five sensors: air temperature and humidity; soil temperature and humidity; and solar radiation), most of its functionalities are dependent on this device, so we considered that this application needs an external sensor. There are also two applications (GPS Fields Area Measure $[67,68]$ and Field Navigator [75]) that support (but do not necessarily require) the use of external GPS receivers for higher location accuracy. Some applications require more advanced external sensors or a set of sensors, for example, weather stations or wireless sensor networks (WSNs). However, these applications are usually only responsible for downloading data from the sensors and forwarding it to a remote server. These applications were not presented in this paper since this is a defined exclusion criterion.

Concerning the possibility of saving and reuse (export and import) data, $20(52.6 \%)$ applications provide this functionality, and $16(42.1 \%)$ do not provide it. For two $(5.3 \%)$ applications, it was not possible to identify if they allow exporting and importing data since they are not available for download and the authors make no reference to it. Exporting and importing data has the advantage of allowing to transfer it to another device or save it for future reference. It also allows importing the data into other standalone tools, for example, GIS applications for more advanced processing.

Finally, regarding the application's interface, $9(23.7 \%)$ have elaborated interfaces with modern and attractive designs, 16 (42.1\%) have interfaces with simple designs, and $13(34.2 \%)$ have little cared interfaces with old and unattractive designs. All (100.0\%) applications are easy to use and do not require that users have specific technological knowledge. Any professional or non-professional farmer with more or fewer qualifications can use them without difficulty. Careful development of application design and interface is important, as it is usually the first characteristic that a user notices when downloading an application. A user is more likely to download an application with a modern and eye-catching design than an application with an untidy and old-fashioned design.

\section{Conclusions and Final Remarks}

The number of applications that assist farmers' decision making is still limited and many of them are still in the development stage. Applications for irrigation management, disease detection, water point management, remote sensor reading, crop yields estimation and mapping, soil type mapping, among many others, have emerged. 
The bibliographic review carried out during this work provides an overview of the application types that exist, what features they provide and how they are a useful tool for farmers in general. It has been found that connectivity is indeed essential and that the ability to process or execute artificial intelligence algorithms locally is an asset, this added to the fact that any modern smartphone is capable of obtaining high-quality images and having an adequate processing capacity.

These capabilities become especially useful and attractive when a mobile device such as a smartphone can indeed be of great use to get near real time agronomic indicators, for example, leaf area measuring, among others. Among all the applications analyzed, it has been concluded that image processing is, in fact, the greatest common denominator, rather than the measurement of agrometeorological parameters. The photographic record and the interpretation or processing of images for the characterization of diseases seem to be the focus of most of the currently existing applications.

It has been found that, given the increase in applications in this field, smartphones constitute a major contribution to the dissemination of applications for use in precision agriculture.

\subsection{Research Challenges}

This systematic review includes not only applications published in scientific documents (obtained through the Scopus, Web of Science, ScienceDirect and IEEE Xplore Digital Library databases) but also applications available on the Google Play and/or the App Store. This allowed for a broader categorization of applications than if only applications published in scientific documents had been used. However, this made the search more challenging due to the difficulty in accurately understanding what the purpose, the functionalities and the sensors that each of them used only based on the description provided by the developers of the application, which often may not even exist. In these cases, it was necessary to install and test the application in order to make a more detailed description of it. Another problem arises related to the filtering of results since for each category there can be hundreds of applications. Therefore, two criteria for exclusion of applications were defined thinking exclusively in the applications available on the Google Play and/or the App Store, excluding from this review applications rated less than 3.5 stars and paid applications.

\subsection{Limitations in Application Development}

There are currently several limitations in the development of mobile applications for use in precision agriculture. The processing capacity (operating time) of the mobile devices themselves is one of the main limitations. DL, ML or AI algorithms and even some image processing techniques require considerable processing capacity, often leading to the need for transfer the data to be processed to a remote server where they are processed and from where a response will be received with the result of the processing. Since in many places where this type of application is used, there may not be an Internet connection, this processing ceases to be done at the moment and in situ and will have to be performed later in a place with an Internet connection. However, when a particular action is dependent on this result, it will imply that the user moves to a location with an Internet connection and then has to move again to the place where the action is performed, which in practice is not efficient.

Another limitation is the size of the mobile device's screen. Ideally, farmers should be able to use the applications on their personal mobile devices instead of having to purchase a mobile device specifically to use them. Although most of today's smartphones have a sizeable screen, there are still devices with smaller screen and, therefore, applications must be prepared to make it easy to interact with them on screens of different dimensions. It should also be bared in mind that these applications can be run on tablets where it may be necessary to adapt their interface.

There is also a generational aspect to take into account when developing this type of applications since the farmers who currently work in the field are people of some age and are not very apt to use technology, implying that the applications developed are the most simple, intuitive and easy to use as possible. 
The last difficulty identified in the development of these applications is related to the difference between the sensors used in each mobile device. The main sensor that imposes these difficulties is the camera, because some of the most advanced image processing algorithms are dependent on the camera's parameters to provide an accurate result. As there are currently a large number of devices with different types of cameras, from different manufacturers and with different lenses, it is difficult to develop applications that work correctly on a large number of devices.

\subsection{Future Trends}

There are currently many applications that are used in the general public domain and not exclusively by professionals. In the near future it is expected that these applications will move to a professional domain and be considered tools for field work. Considering that the group of professionals that will use this type of applications, most of the time have little or practically no knowledge in the technological area, it is expected that the applications will maintain the level of simplicity and ease of use. However, this is a problem that tends to be resolved over time as new generations of farmers already have proficiency to efficiently use these applications. In short, more professional applications are expected but which still do not require a great IT proficiency by those who use them. For that, it will be necessary to create criteria and usability standards that applications will have to respect so that they can be considered a work tool and not just applications for enthusiasts and "entertainment". It is expected that these future work tools will be based on the entertainment applications that have been tested and improved over several years. It is also expected an increasing migration of software that currently runs on computers to applications installable on mobile devices or web-based applications.

With the increase in the processing power of mobile devices, applications are also expected to use DL, ML and AI techniques on the smartphone itself, thus avoiding the impossibility of using applications in remote locations where there may be no Internet connection. In this way, it is expected that the applications can be used offline and that they can later transfer the information to a remote server so it can be accessed through different devices.

It is also speculated that the emergence of equipment equipped with image sensors that allow capturing wavelengths that go beyond the visible spectrum will open new horizons for this type of applications. Mobile phones equipped with cameras that allow the capture of the spectrum in the infrared and near-infrared zones will allow the implementation of vegetative vigor determination applications allowing the creation of, for example, NDVI maps.

Author Contributions: Conceptualization, J.M. and R.M.; methodology, T.M.P., F.N.d.S. and M.C.; validation, T.M.P., M.C. and J.B.-C.; formal analysis, E.P. and J.J.S.; investigation, J.M.; writing-original draft preparation, J.M. and T.M.P.; writing-review and editing, J.M. and R.M.; visualization, J.B.-C.; supervision, R.M. and F.N.d.S.; project administration, R.M.; funding acquisition, R.M. and F.N.d.S. All authors have read and agreed to the published version of the manuscript.

Funding: This research was partial funded by ERDF and North 2020-North Regional Operational Program, as part of project "INNOVINE\&WINE-Vineyard and Wine Innovation Platform" (NORTE-01-0145FEDER-000038), by the ERDF-European Regional Development Fund through the Operational Programme for Competitiveness and Internationalisation-COMPETE 2020 Programme within project POCI-01-0145FEDER-006961, by National Funds through the FCT-Fundação para a Ciência e a Tecnologia (Portuguese Foundation for Science and Technology) as part of project UID/EEA/50014/2013, and by FCT as part of the doctoral fellowship with the reference SFRH/BD/129813/2017.

Conflicts of Interest: The authors declare no conflict of interest.

\section{Abbreviations}

The following abbreviations are used in this manuscript: 


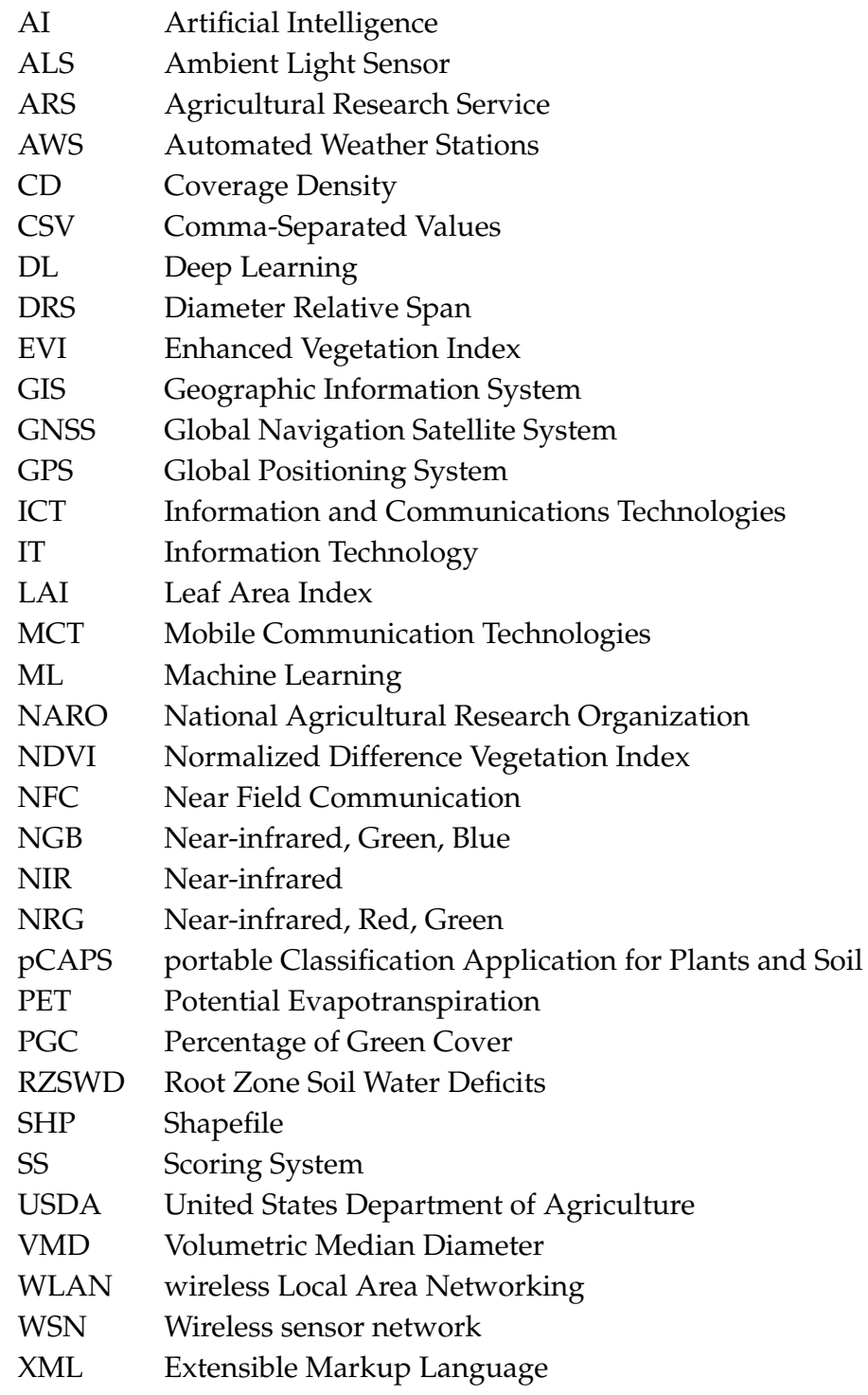

\section{References}

1. Da Cruz, S.M.S.; Vieira, A.C.D.M.; Marques, M.M. Technological Management of Small Crops Through Mobile Apps and Precision Agriculture. In Proceedings of the Annual Conference on Brazilian Symposium on Information Systems: Information Systems: A Computer Socio-Technical Perspective (SBSI 2015), Goiania, Brazil, 26-29 May 2015; Volume 1, pp. 379-386.

2. Kasey P. Gartner Top 10 Strategic Technology Trends for 2018. Available online: https:/ /www.gartner.com/ smarterwithgartner/gartner-top-10-strategic-technology-trends-for-2018 (accessed on 4 November 2019).

3. Statista. Number of Mobile App Downloads Worldwide in 2016, 2017 and 2021, by Store. Available online: https:/ / www.statista.com/statistics/276602/annual-number-of-mobile-app-downloads-by-store/ (accessed on 30 October 2019).

4. Rita, I.G. A InfluêNcia das AplicaçõEs Móveis na Percepção da Imagem de Marcas Comerciai-A Perspectiva dos Consumidores. Master's Thesis, Universidade Europeia-Laureate International Universities, Lisbon, Portugal, June 2016. Available online: http://hdl.handle.net/10400.26/14350 (accessed on 4 November 2019).

5. Patel, H.; Patel, D. Survey of android apps for agriculture sector. Int. J. Inf. Sci. Tech. 2016, 6, 61-67. [CrossRef] 
6. Kuharić, D.; Bubalo, A.; Galić, A. Mobile applications in agriculture. In Proceedings of the 10th International Scientific/Professional Conference, Agriculture in Nature and Environment Protection, Vukovar, Croatia, 5-7 June 2017; pp. 237-242.

7. Arroqui, M.; Mateos, C.; Machado, C.; Zunino, A. RESTful Web Services improve the efficiency of data transfer of a whole-farm simulator accessed by Android smartphones. Comput. Electron. Agric. 2012, 87, 14-18. [CrossRef]

8. Brugger, F. Mobile Applications in Agriculture; Syngenta Foundation: Basel, Switzerland, 2011; pp. 1-38.

9. Mittal, S.; Gandhi, S.; Tripathi, G. Socio-Economic Impact of Mobile Phones on Indian Agriculture; Working Paper, No. 246; Indian Council for Research on International Economic Relations (ICRIER): New Delhi, India, 2010. Available online: http:/ / hdl.handle.net/10419/176264 (accessed on 6 November 2019).

10. Csótó, M. Mobile devices in agriculture: Attracting new audiences or serving the tech-savvy? J. Agric. Inform. 2015, 6, 75-84. [CrossRef]

11. Kuhlmann, F.; Berg, E. The Farm as an Enterprise-The European Perspective. In Proceedings of the 13th International Farm Management Congress, Wageningen, The Netherlands, 7-12 July 2002; pp. 1-10.

12. Maréchal, N. What Do We Mean by Mobile Ecosystems? Available online: https:/ / rankingdigitalrights.org/ 2016/09/15/what-are-mobile-ecosystems / (accessed on 23 January 2020).

13. Statista. Number of Apps Available in Leading App Stores as of 3rd Quarter 2019. Available online: https: / www.statista.com/statistics/276623/number-of-apps-available-in-leading-app-stores / (accessed on 23 January 2020).

14. Statista. Distribution of Free and Paid Apps in the Apple App Store and Google Play as of December 2019. Available online: https:/ / www.statista.com/statistics/263797/number-of-applications-for-mobile-phones / (accessed on 23 January 2020).

15. Google Developers. Connectivity Overview. Available online: https://developer.android.com/guide/ topics / connectivity (accessed on 7 November 2019).

16. Google Developers. Sensors Overview. Available online: https://developer.android.com/guide/topics/ sensors/sensors_overview (accessed on 7 November 2019).

17. Karetsos, S.; Costopoulou, C.; Sideridis, A. Developing a smartphone app for m-government in agriculture. J. Agric. Inform. 2014, 5, 1-8. [CrossRef]

18. Morais, R.; Silva, N.; Mendes, J.; Adão, T.; Pádua, L.; López-Riquelme, J.A.; Pavón-Pulido, N.; Sousa, J.J.; Peres, E. mySense: A comprehensive data management environment to improve precision agriculture practices. Comput. Electron. Agric. 2019, 162, 882-894. [CrossRef]

19. Bambini, M.D.; Luchiari-Júnior, A.; Romani, L.A.S. Mercado de aplicativos móveis (apps) para uso na agricultura. In Proceedings of the Simpósio Nacional de Instrumentação Agropecuária (SIAGRO 2014), São Carlos, Brazil, 18-20 November 2014; pp. 711-714.

20. Pongnumkul, S.; Chaovalit, P.; Surasvadi, N. Applications of smartphone-based sensors in agriculture: A systematic review of research. J. Sens. 2015, 2015, 1-18. [CrossRef]

21. Plantix. The Smart Crop Assistant on Your Smartphone. Available online: https://plantix.net/ (accessed on 7 October 2019).

22. International Crops Research Institute for the Semi-Arid Tropics. Mobile App to Help Farmers Overcome Crop Damage. Available online: http://www.icrisat.org/mobile-app-to-help-farmers-overcome-cropdamage/ (accessed on 25 May 2020).

23. BioLeaf. Foliar Analysis ${ }^{\mathrm{TM}}$. Available online: http:// bioleaf.icmc.usp.br/ (accessed on 7 October 2019).

24. Machado, B.B.; Orue, J.P.; Arruda, M.S.; Santos, C.V.; Sarath, D.S.; Goncalves, W.N.; Silva, G.G.; Pistori, H.; Roel, A.R.; Rodrigues, J.F., Jr. BioLeaf: A professional mobile application to measure foliar damage caused by insect herbivory. Comput. Electron. Agric. 2016, 129, 44-55. [CrossRef]

25. Reddy, S.; Pawar, A.; Rasane, S.; Kadam, S. A Survey on Crop Disease Detection and Prevention using Android Application. Int. J. Innov. Sci. Eng. Technol. 2015, 2, 621-626.

26. ADAMA. ADAMA Bullseye. Available online: https://www.adama.com/us/en/adama-bullseye (accessed on 25 May 2020).

27. Macmillan, C. PMapp: A Mobile App for Assessing Powdery Mildew. Available online: http://www. vineyardteam.org/files/resources/PMapp.pdf (accessed on 9 October 2019). 
28. Scott, E.S.; Powell, S.; Evans, K.; Barry, K.; Petrovic, T.; Kravchuk, O.; Zanker, T.; Evans, K.J. Digital tools to facilitate assessing powdery mildew on grape bunches. In Proceedings of the 21st Australasian Plant Pathology Society Biennial Conference: Science Protecting Plant Health, Brisbane, Australia, 26-28 September 2017; p. 142.

29. Petrellis, N. A smart phone image processing application for plant disease diagnosis. In Proceedings of the 6th International Conference on Modern Circuits and Systems Technologies (MOCAST 2017), Thessaloniki, Greece, 4-6 May 2017; pp. 1-4.

30. Petrellis, N. Plant Disease Diagnosis for Smart Phone Applications with Extensible Set of Diseases. Appl. Sci. 2019, 9, 1952. [CrossRef]

31. ImScope. Application for Android and An Experimental Tool Oriented to Visualization and Recording of Indicators of Plant Health. Available online: https:/ / www.idoneos.com/procesamiento_de_imagenes / imscope/imscope_(english).html (accessed on 9 October 2019).

32. Buinickaitè, A. Crop Problem Identification-Quick and Easy. Available online: https://blog.farmis.lt/cropproblem-identification-quick-and-easy-3be14752fd8c (accessed on 25 May 2020).

33. Machado, B.B.; Spadon, G.; Arruda, M.S.; Goncalves, W.N.; Carvalho, A.C.; Rodrigues-Jr, J.F. A smartphone application to measure the quality of pest control spraying machines via image analysis. In Proceedings of the 33rd Annual ACM Symposium on Applied Computing (SAC'18), Pau, France, 9-13 April 2018; pp. 956-963.

34. Hefty, D.; Hefty, B. Ag PhD Crop Nutrient Deficiencies App Now Available! Available online: http:/ / www.agphd.com/resources/ag-phd-mobile-apps/ag-phd-crop-nutrient-deficiencies/ (accessed on 12 November 2019).

35. Yara International ASA. Farmer's Toolbox TankmixIT. Available online: https://www.yara.co.uk/cropnutrition/farmers-toolbox/tankmixit/ (accessed on 12 November 2019).

36. TeeJet Technologies. SpraySelect. Available online: https://www.teejet.com/tools/index.aspx (accessed on 25 May 2020).

37. Ferguson, J.C.; Chechetto, R.G.; O’Donnell, C.C.; Fritz, B.K.; Hoffmann, W.C.; Coleman, C.E.; Chauhan, B.S.; Adkins, S.W.; Kruger, G.R.; Hewitt, A.J. Assessing a novel smartphone application-SnapCard, compared to five imaging systems to quantify droplet deposition on artificial collectors. Comput. Electron. Agric. 2016, 128, 193-198. [CrossRef]

38. Bueno-Delgado, M.V.; Molina-Martínez, J.M.; Correoso-Campillo, R.; Pavón-Mariño, P. Ecofert: An Android application for the optimization of fertilizer cost in fertigation. Comput. Electron. Agric. 2016, 121, $32-42$. [CrossRef]

39. Vellidis, G.; Liakos, V.; Andreis, J.H.; Perry, C.D.; Porter, W.M.; Barnes, E.M.; Morgan, K.T.; Fraisse, C.; Migliaccio, K.W. Development and assessment of a smartphone application for irrigation scheduling in cotton. Comput. Electron. Agric. 2016, 127, 249-259. [CrossRef]

40. Skewes, M.; Petrie, P.R.; Liu, S.; Whitty, M. Smartphone tools for measuring vine water status. In Proceedings of the International Symposium on Sensing Plant Water Status-Methods and Applications in Horticultural Science (SPWS 2016), Potsdam, Germany, 5-7 October 2016; pp. 53-58.

41. Petrie, P.R.; Wang, Y.; Liu, S.; Lam, S.; Whitty, M.A.; Skewes, M.A. The accuracy and utility of a low cost thermal camera and smartphone-based system to assess grapevine water status. Biosyst. Eng. 2019, 179, 126-139. [CrossRef]

42. American Society for Enology and Viticulture. A Thermal Camera-Based Smartphone Application to Measure Vine Water Status. Available online: http:/ / www.asev.org/abstract/thermal-camera-based-smartphoneapplication-measure-vine-water-status (accessed on 16 October 2019).

43. Hernández-Hernández, J.L.; Ruiz-Hernández, J.; García-Mateos, G.; González-Esquiva, J.M.; Ruiz-Canales, A.; Molina-Martínez, J.M. A new portable application for automatic segmentation of plants in agriculture. Agric. Water. Manag. 2017, 183, 146-157. [CrossRef]

44. García-Mateos, G.; Hernández-Hernández, J.L.; Escarabajal-Henarejos, D.; Jaén-Terrones, S.; Molina-Martínez, J.M. Study and comparison of color models for automatic image analysis in irrigation management applications. Agric. Water. Manag. 2015, 151, 158-166. [CrossRef]

45. Júnior, W.M.; Valeriano, T.T.B.; de Souza Rolim, G. EVAPO: A smartphone application to estimate potential evapotranspiration using cloud gridded meteorological data from NASA-POWER system. Comput. Electron. Agric. 2019, 156, 187-192. 
46. Fuentes, S.; De Bei, R.; Pozo, C.; Tyerman, S. Development of a smartphone application to characterise temporal and spatial canopy architecture and leaf area index for grapevines. Wine Vitic. J. 2012, 6, 56-60.

47. Fuentes, S.; Poblete-Echeverría, C.; Ortega-Farias, S.; Tyerman, S.; De Bei, R. Automated estimation of leaf area index from grapevine canopies using cover photography, video and computational analysis methods. Aust. J. Grape Wine Res. 2014, 20, 465-473. [CrossRef]

48. De Bei, R.; Fuentes, S.; Gilliham, M.; Tyerman, S.; Edwards, E.; Bianchini, N.; Smith, J.; Collins, C. VitiCanopy: A free computer App to estimate canopy vigor and porosity for grapevine. Sensors 2016, 16, 585. [CrossRef]

49. Easlon, H.M.; Bloom, A.J. Easy Leaf Area: Automated digital image analysis for rapid and accurate measurement of leaf area. Appl. Plant Sci. 2014, 2. [CrossRef]

50. Easlon, H.M. Easy-Leaf-Area. Available online: https://github.com/heaslon/Easy-Leaf-Area (accessed on 20 December 2019).

51. Easlon, H.M. Canopy Cover Free (Version 1.0.3-2016). Available online: https://play.google.com/store/ apps / details?id=com.heaslon.canopycover (accessed on 15 October 2019).

52. Patrignani, A.; Ochsner, T.E. Canopeo: A powerful new tool for measuring fractional green canopy cover. Agron. J. 2015, 107, 2312-2320. [CrossRef]

53. Canopeo. Rapid and Accurate Green Canopy Cover Measurement Tool. Available online: http://www. canopeoapp.com/ (accessed on 15 October 2019).

54. Booth, D.T.; Cox, S.E.; Berryman, R.D. Point sampling digital imagery with "SamplePoint". Environ. Monit. Assess. 2006, 123, 97-108. [CrossRef] [PubMed]

55. Systat Software. SigmaScan Pro-Analyze Images Automatically. Available online: https://systatsoftware. com/products/sigmascan/ (accessed on 20 December 2019).

56. Confalonieri, R.; Foi, M.; Casa, R.; Aquaro, S.; Tona, E.; Peterle, M.; Boldini, A.; De Carli, G.; Ferrari, A.; Finotto, G.; et al. Development of an app for estimating leaf area index using a smartphone. Trueness and precision determination and comparison with other indirect methods. Comput. Electron. Agric. 2013, 96, 67-74. [CrossRef]

57. Confalonieri, R.; Francone, C.; Foi, M. The PocketLAI smartphone app: An alternative method for leaf area index estimation. In Proceedings of the 7th International Congress on Environmental Modelling and Software (iEMSs 2014), San Diego, CA, USA, 15-19 June 2014; pp. 288-293.

58. Orlando, F.; Movedi, E.; Coduto, D.; Parisi, S.; Brancadoro, L.; Pagani, V.; Guarneri, T.; Confalonieri, R. Estimating leaf area index (LAI) in vineyards using the PocketLAI smart-app. Sensors 2016, 16, 2004. [CrossRef] [PubMed]

59. Sinergise. Sentinel-2 NDVI Maps—Sentinel App for Android. Available online: http:/ /www.sentinel-hub. com/explore/industries-and-showcases/sentinel-2-ndvi-maps (accessed on 15 October 2019).

60. OneSoil. Make Reliable Agricultural Decisions with AI. Available online: https:// onesoil.ai/en/ (accessed on 12 November 2019).

61. Bauer, J.; Siegmann, B.; Jarmer, T.; Aschenbruck, N. Smart fLAIr: A smartphone application for fast LAI retrieval using ambient light sensors. In Proceedings of the 2016 IEEE Sensors Applications Symposium (SAS 2016), Catania, Italy, 20-22 April 2016; pp. 1-6.

62. Huning, L.; Bauer, J.; Aschenbruck, N. A Privacy Preserving Mobile Crowdsensing Architecture for a Smart Farming Application. In Proceedings of the First ACM Workshop on Mobile Crowdsensing Systems and Applications (CrowdSenSys'17), Delft, The Netherlands, 5 November 2017; pp. 62-67.

63. Aquino, A.; Millan, B.; Gaston, D.; Diago, M.P.; Tardaguila, J. vitisFlower ${ }^{\circledR}$ : Development and testing of a novel Android-smartphone application for assessing the number of grapevine flowers per inflorescence using artificial vision techniques. Sensors 2015, 15, 21204-21218. [CrossRef]

64. Aquino, A.; Barrio, I.; Diago, M.P.; Millan, B.; Tardaguila, J. vitisBerry: An Android-smartphone application to early evaluate the number of grapevine berries by means of image analysis. Comput. Electron. Agric. 2018, 148, 19-28. [CrossRef]

65. Wang, Z.; Koirala, A.; Walsh, K.; Anderson, N.; Verma, B. In Field Fruit Sizing Using A Smart Phone Application. Sensors 2018, 18, 3331. [CrossRef]

66. Carvalho, P. As Apps NA Agricultura-Agri Precision. Abolsamia, 105, March and April 2017 ; p. 98. Available online: https:/ /issuu.com/abolsamia/docs/abolsamia_105/98 (accessed on 17 October 2019). 
67. Buinickaitè, A. 2,5M Farmers Are Already Measuring Their Fields for Free. Available online: https:/ /blog.farmis.lt/2-5m-farmers-are-already-measuring-their-fields-for-free-4908bc0ee0a0 (accessed on 25 May 2020).

68. Randytè, A. Why Measuring and Tracking the Field Is So Important? Available online: https://blog.farmis. 1t/why-measuring-and-tracking-the-field-is-so-important-4b949bca2acb (accessed on 25 May 2020).

69. Farmis. Soil Sampler (Version 1.0.10-2018). Available online: https://play.google.com/store/apps/details? $\mathrm{id}=$ com.noframe.farmissoilsamples (accessed on 17 October 2019).

70. Delgado, J.A.; Kowalski, K.; Tebbe, C. The first Nitrogen Index app for mobile devices: Using portable technology for smart agricultural management. Comput. Electron. Agric. 2013, 91, 121-123. [CrossRef]

71. Delgado, J.A.; Gagliardi, P.M.; Rau, E.J.; Fry, R.; Figueroa, U.; Gross, C.; Cueto-Wong, J.; Shaffer, M.J.; Kowalski, K.; Neer, D.; et al. Nitrogen Index 4.4, User Manual. 2011. Available online: https:/ /vtechworks. lib.vt.edu/bitstream/handle/10919/69932/4975_Nitrogen_Index_4_4_User_Manual_final.pdf (accessed on 17 October 2019).

72. Agri Info Design. AgriBus-NAVI: GPS Guidance System to Mount on Agricultural Machinery. Available online: https: / /agri-info-design.com/en/agribus-navi/ (accessed on 22 October 2019).

73. Hamada, Y.; Matsuo, Y.; Yamashita, T. Agricultural Vehicle Navigation System. Jpn. Agric. Res. Q. 2009, 43, 187-192. [CrossRef]

74. Yamamoto, S.; Matsuo, Y.; Hamada, Y.; Yukimoto, O. Farm Operation-Supporting Program, Operation Navigator for Agricultural Vehicle and Farm Operation-Supporting Method. Japanese Patent JP4572417B2, 4 November 2010.

75. Buinickaite, A. Are Large Investments Necessary to Obtain the Benefits of Precision Farming? Available online: https:/ / blog.farmis.lt/how-field-navigator-can-help-a-farmer-94aaadf11ae6 (accessed on 25 May 2020).

76. Lantzos, T.; Koykoyris, G.; Salampasis, M. FarmManager: An Android application for the management of small farms. In Proceedings of the 6th International Conference on Information and Communication Technologies in Agriculture, Food and Environment (HAICTA 2013), Corfu Island, Greece, 19-22 September 2013; pp. 587-592.

77. Agroop. Agroop Cooperation-Crop Monitoring. Available online: https://www.agroop.net/en/ whatwedo\#cooperation (accessed on 13 November 2019).

78. AgriApp Technologies. AgriApp-Connecting Farmers. Available online: http://agriapp.co.in/ (accessed on 24 October 2019).

79. Zargar, H. AgriApp: An App for Farmers to Help Them Improve Crop Output. Available online: https:/ / www.livemint.com/Technology/btn0QkaCI3rBtdotyiQdfL/AgriApp-An-app-for-farmers-tohelp-them-improve-crop-output.html (accessed on 25 May 2020).

(C) 2020 by the authors. Licensee MDPI, Basel, Switzerland. This article is an open access article distributed under the terms and conditions of the Creative Commons Attribution (CC BY) license (http://creativecommons.org/licenses/by/4.0/). 